\title{
DESEMPENHO DE FRANGOS DE CORTE ALIMENTADOS COM NÍVEIS CRESCENTES DA MISTURA DOS ÁCIDOS ORGÂNICOS FÓRMICO E PROPIÔNICO (70\%:30\%)
}

\section{MARCOS MARTINEZ DO VALE \\ Zootecnista}

Dissertação apresentada à Escola Superior de Agricultura "Luiz de Queiroz", Universidade de São Paulo, para obtenção do título de Mestre em Agronomia. Área de Concentração: Ciência Animal e Pástagens.

PIRACICABA

Estado de São Paulo

Abril - 1998 
Dados Internacionais de Catalogaçāo na Publicaçāo (CIP) DIVISĀO DE BIBLIOTECA E DOCUMENTAÇĀO - Campus "Luiz de Oueiroz"/USP

Vale, Marcos Martinez do

Desempenho de frangos de corte alimentados com niveis crescentes da mistura dos ácidos orgânicos fórmico e propiônico (70\%:30\%) / Marcos Martinez do Vale. . Piracicaba, 1998.

$52 \mathrm{p}$.

Dissertaçāo (mestrado) -. Escola Superior de Agricultura Luiz de Queiroz, 1998. Bibliografia.

1. Ácido fórmico 2. Ácido orgânico 3. Ácido propiônico 4. Frango de corte 5. Desempenho animal I. Título 
Para Ivone e Roberta por estarem sempre presentes

e pelo carinho

Dedico

Às "meninas" Mônica e Michele e ao amigo

Poti pela convivência e grande apoio

Ofereço

"O ser humano fatalmente colherá aquilo que plantar" 


\section{AGRADECIMENTOS}

À FAPESP pelo financiamento do projeto.

À CAPES pela bolsa de estudo.

Ao Prof. José Fernando Machado Menten pelo apoio, orientação e ensino.

Aos funcionários do Dep. De Zootecnia de Não-Ruminantes pelo apoio competente e amizade.

Às secretárias do Dep. De Zootecnia de Não-Ruminantes Vera e Claudia pela paciência.

Aos Docentes do Curso de Ciência Animal e Pastagens, em especial aos do Dep. De Zootecnia de Não-Ruminantes e à ESALQ/USP pela oportunidade.

Aos amigos que tornaram a vivência mais feliz nesta cidade. Que fique o compromisso de apoio mútuo entre nós.

A Deus. 


\section{SUMÁRIO}

Página

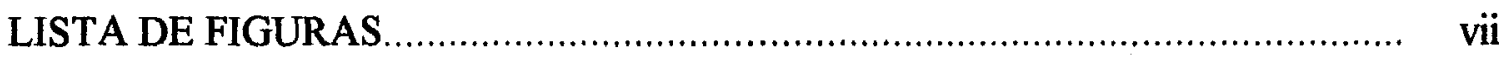

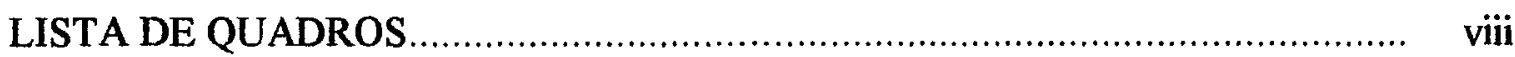

RESUMO

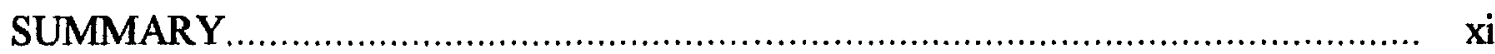

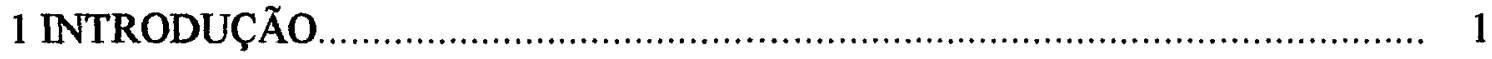

2 REVISÃO DE LITERATURA ................................................................ 4

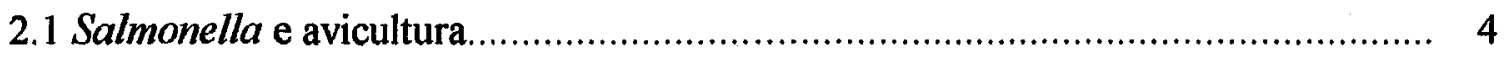

2.2 Fontes de contaminação............................................................................ 5

2.3 Rações como fonte de contaminação por Salmonella.......................................... 6

2.4 Uso de agentes antimicrobianos................................................................ 8

2.5 Ácidos orgânicos na alimentação de aves...................................................... 10

2.5.1 Definição e química de AOs..................................................................... 11

2.5.2 Efeitos e modo de ação dos AOs como antimicrobianos................................. 12

2.5.3 Desempenho e metabolismo de aves alimentadas com AOs........................... 15

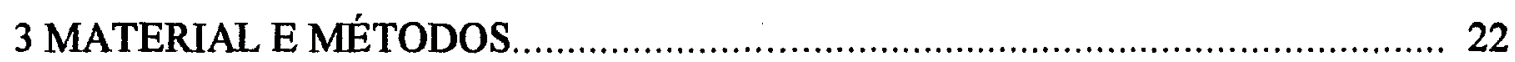

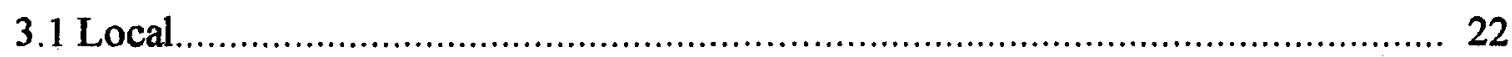

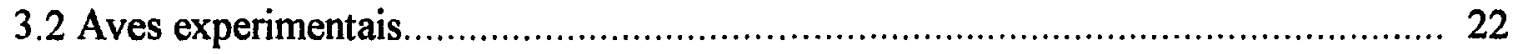

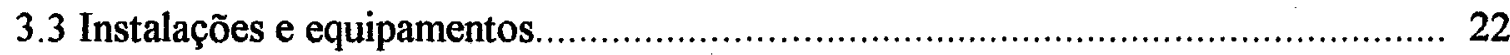

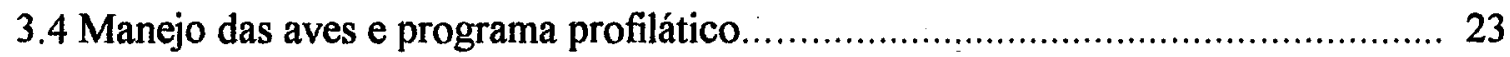


Página

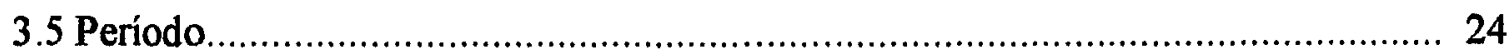

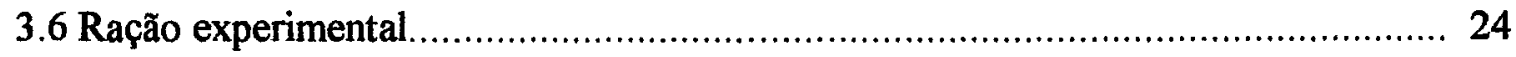

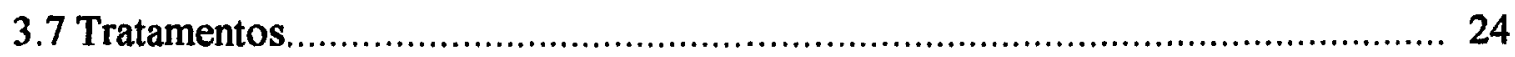

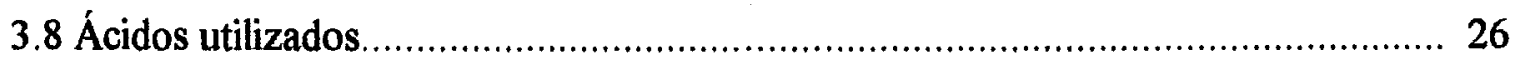

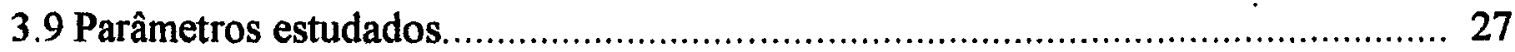

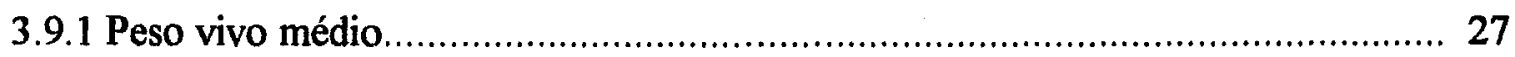

3.9.2 Ganho de peso médio............................................................................ 27

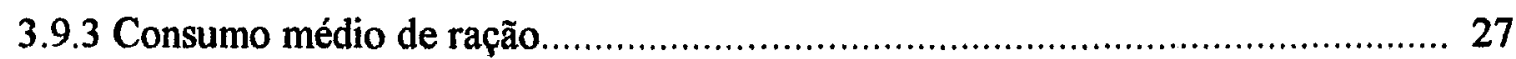

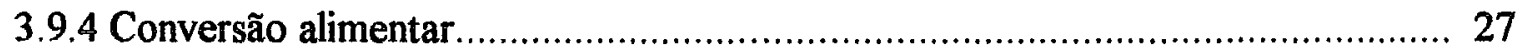

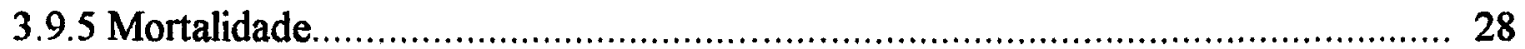

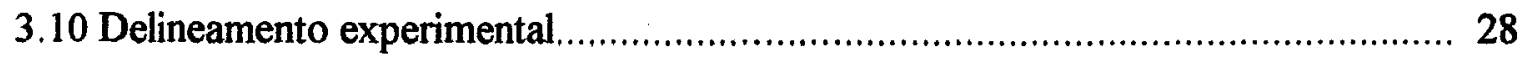

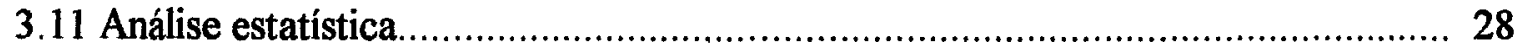

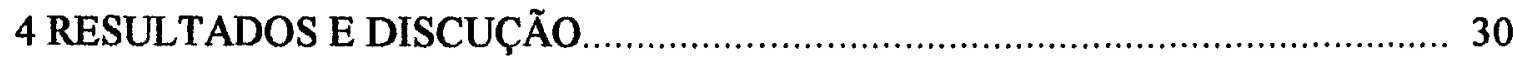

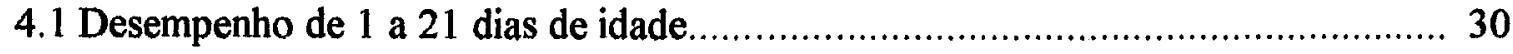

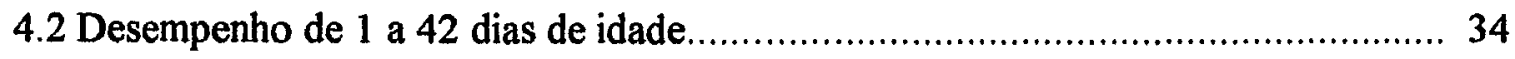

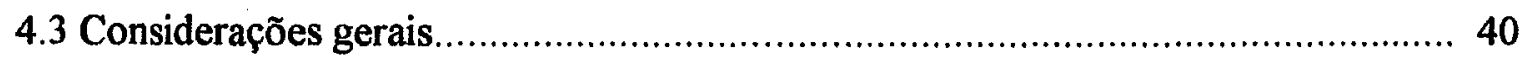

5 CONCLUSÕES

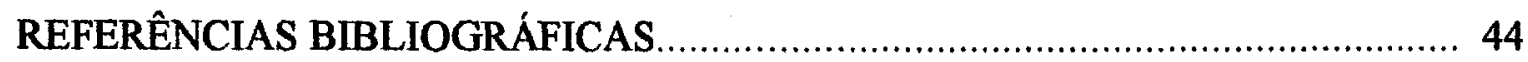




\section{LISTA DE FIGURAS}

Página

1. Efeito dos AOs sobre o peso vivo aos 21 dias de idade.

2. Efeito dos AOs sobre o consumo de ração de 1 a 21 dias de idade. 32

3. Efeito dos AOs sobre o ganho de peso de 1 a 21 dias de idade. 33

4. Efeito dos AOs sobre o consumo de ração de 1 a 42 dias de idade. 37 


\section{LISTA DE QUADROS}

Página

1. Valores de pK de alguns ácidos orgânicos. 12

2. Média das temperaturas mínima e máxima observadas no período experimental 23

3. Composição percentual e niveis nutricionais calculados das dietas basais. 25

4. Desempenho das aves de 1 a 21 dias de idade. 30

5. Desempenho das aves de 1 a 42 dias de idade. 35

6. Desempenho das aves de 22 a 42 dias de idade 38 


\title{
DESEMPENHO DE FRANGOS DE CORTE ALIMENTADOS COM NIVEIS CRESCENTES DA MISTURA DOS ÁCIDOS ORGÂNICOS FÓRMICO E PROPIÔNICO (70\%:30\%)
}

\author{
Autor: MARCOS MARTINEZ DO VALE \\ Orientador: Prof. JOSÉ FERNANDO MACHADO MENTEN
}

\section{RESUMO}

Avaliou-se o desempenho de frangos de corte machos de 1 a 42 dias de idade recebendo níveis crescentes $(0,0,25,0,50,1,0$ e 2,0\%) da mistura dos ácidos orgânicos (AOs) fórmico e propiônico (70\%:30\%) na ração. Foi utilizado o delineamento inteiramente ao acaso com 5 tratamentos e 5 repetições com 40 aves por unidade experimental. As rações foram baseadas em milho, farelo de soja e óleo de soja, com os niveis nutricionais e de composição dos alimentos estabelecidos segundo Rostagno et al. (1994) e os tratamentos foram adicionados à dieta basal em substituição ao amido. As aves foram mantidas em galpão convencional de alvenaria dividido em 25 boxes e alimentadas à vontade. Os resultados foram submetidos à análise de regressão polinomial.

De 1 a 21 dias de idade foram afetados de forma quadrática $(\mathrm{P}<0,05)$ o peso vivo, ganho de peso e consumo de ração. $O$ peso vivo e ganho de peso foram pouco reduzidos com a inclusão de até $1 \%$ de AOs na ração, no nível de $2 \%$ ocorreu uma redução mais acentuada. $O$ consumo de ração aumentou com 0,25 e $0,5 \%$ de inclusão dos AOs e reduziu com $2 \%$ de inclusão. A conversão alimentar não foi afetada significativamente $(\mathrm{P}>0,05)$. 
Para o período de 1 a 42 dias de criação, apenas o consumo de ração foi afetado pelos tratamentos apresentando um comportamento quadrático $(\mathrm{P}=0,08)$, aumentando nos níveis de 0,25 e $0,5 \%$, se equiparam ao controle no nível de $1 \%$ e sendo reduzido de forma mais acentuada até $2 \%$ dos AOs. De 22 a 42 dias de idade nenhuma diferença significativa $(P>0,05)$ foi observada no desempenho e, para todas as fases, houve uma tendência de piora na conversão alimentar para os níveis de 0,25 e $0,5 \%$ de AOs e de melhora com o nível de $2 \%$ de inclusão dos ácidos. Pelo presente estudo conclui-se que a mistura dos ácidos fórmico e propiônico (70\%:30\%) afetou o desempenho das aves, o nível de $1 \%$ de inclusão proporcionou desempenho similar ao das aves não tratadas e seu uso é dependente da necessidade da aplicação destes ácidos e de fatores econômicos. 


\title{
PERFORMANCE OF FED BROILER CHICKENS WITH GROWING LEVELS OF THE MIXTURE OF THE ORGANIC ACIDS FORMIC AND PROPIONIC
} (70\%:30\%)

\author{
Author: MARCOS MARTINEZ DO VALE \\ Adviser: Prof. JOSÉ FERNANDO MACHADO MENTEN
}

\section{SUMMARY}

The performance of male broiler chickens was evaluated from 1 to 42 days of age receiving levels $(0,0.25,0.50,1.0$ and $2.0 \%)$ of the mixture of the organic acids (OAs) formic and propionic (70\%:30\%) in the ration. The experimental design was completely randomized with 5 treatments and 5 replicates with 40 birds each. The diets were based on corn, soybean meal and soy oil, with the nutritional levels and of composition of the feeds established according to Rostagno et al. (1994) and the OAs were added to the basal diet in substitution to the starch. The birds were maintained in a conventional broiler house divided in 25 boxes and fed ad libitum. The results were submitted to the analysis of polynomial regression.

Body weigth, weight gain and feed intake from 1 to 21 days of age were affected quadratically $(\mathrm{P}<0.05)$ by treatements. The body weight and weight gain were not much affected with the inclusion of up to $1 \%$ of OAs in the feed, but the level of $2 \%$ caused an accentuated reduction. The feed intake increased with $0.25 \%$ and $0.5 \%$ of inclusion of OAs and was reduced with $2 \%$ of inclusion. 
For the period from 1 to 42 days, only the feed intake was affected by the treatments, showing a quadratic effect $(\mathrm{P}=0.08)$, increasing in the levels of $0.25 \%$ and $0.5 \%$, the level $1 \%$ was equal to control and reducing with the inclusion of up to $2 \%$ of OAs. From 22 to 42 days of age no significant differences $(P>0.05)$ were observed in the performance and, for all the phases, there was a tendency for worse feed conversion with the levels of $0.25 \%$ and $0.5 \%$ of OAs and improvement with the level of $2 \%$ of inclusion of the acids. The present study demonstrated that the higer inclusions of mixture of the formic and propionic acids (70\%:30\%) affected the performance of the birds, the level of $1 \%$ of inclusion provided similar performance to the control birds and its use is dependent of the need of the application of these acids and of economic factors. 


\section{INTRODUÇÃO}

O consumo mundial de carne de aves passou de 4,5 milhões em 1964 para 51 milhões de toneladas em 1997. Este salto nas três últimas décadas é atribuido ao fato de a carne das aves ter se tornado barata, à tecnificação, crescimento da produção e por se caracterizar como uma proteína animal saudável aliado a um "marketing" favorável (Desouzart, 1997).

A grande expansão da avicultura exigiu o incremento do uso de promotores de crescimento como antibióticos e quimioterápicos usados em níveis subterapêuticos. $\mathrm{O}$ uso indiscriminado destes promotores de crescimento tem favorecido o surgimento de linhagens de enterobactérias resistentes, principalmente em países onde o uso de promotores de crescimento é mais intenso. Isto se agrava pela transferência de resistência entre enterobactérias como Escherichia coli ou Salmonella sp. (Smith, 1975). Este autor relata a recomendação de órgãos norte americano e do Reino Unido para que, apenas os antibióticos com pequena ou nenhuma aplicação terapêutica para o homem, ou que não produzam resistência cruzada, devem ser usado em rações para animais.

O crescimento da avicultura trouxe consigo grandes problemas sanitários, dentre eles as salmoneloses, provocadas por enterobactérias patogênicas para várias espécies animais incluindo aves e o homem.

Um estudo realizado por Fageberg (1986) com aproximadamente 10 mil animais, sendo eles aves, suínos e bovinos, constatou que $5 \%$ das aves e dos suínos estavam contaminados por Salmonella e que para o gado a contaminação foi de $9 \%$. 
Bosquirole $^{1}$ (citado por Silva, 1997) realizou levantamento em vários segmentos de uma integradora no estado de São Paulo, sem histórico para salmoneloses. Foram encontrados 520 amostras positivas, sendo que, dos frangos abatidos $21,6 \%$ estavam contaminados (21 positivos em 97 amostras).

A contaminação dos produtos de origem animal para o consumo humano causando infeções em consumidores tem sido freqüente em várias partes do mundo e motivo de preocupação de órgãos governamentais em função de vultosos gastos médicos e perdas de produtividade (Silva, 1997). Por outro lado a contaminação das aves por salmonelas pode ocorrer por várias formas, as próprias aves são o maior reservatório do patógeno no ambiente e a ingestão de alimento contaminado pode representar o principal meio de contaminação (Westerfeld et al., 1970).

Vários pesquisadores (Berchieri Jr., 1983; Berchieri Jr. et al., 1984; Oliveira, 1996) têm concordado em que uma das principais formas de contaminação é por intermédio do alimento das aves.

Oliveira (1996) testou várias combinações de ácidos orgânicos para evitar a contaminação de pintos de um dia por Salmonella constatando que a mistura de ácido fórmico e propiônico (70\% e 30\%, respectivamente) foi eficiente na eliminação de $S$. enteritidis e $S$. thyphimurium, as de maior importância para saúde pública.

A portaria $n^{\mathrm{o}}$ 1- DINAL/MS de 28 de janeiro de 1987 (Brasil, 1987) determina como padrão microbiológico para alimentos destinados ao consumo humano ausência de Salmonella em $25 \mathrm{~g}$ ou $\mathrm{ml}$ de amostra.

$\mathrm{O}$ uso de ácidos orgânicos em dietas para aves é boa alternativa para minimizar problemas com relação às salmonelas e suas conseqüências com relação à saúde pública.porém, o uso destes ácidos como aditivos em dietas de frangos de corte tem sido questionado; alguns pesquisadores (Voet et al. ${ }^{2}$ citados por Izat et al., 1990a;

\footnotetext{
${ }^{1}$ BOSQUIROLE, S. L. Campinas-SP, 1996. Dissertação (Mestrado). Faculdade de Engenharia de Alimentos-UNICAMP.

${ }^{2}$ VOET, H.; MATHEUS, S.; HARNISCH, S. The effect of organic acids in the rations on the performance of broilers and laying hens. Arch. Geffugelkd, c. 45, p. 221-232, 1981.
} 
Patten \& Waldroup, 1988; Runho et al., 1997) encontraram melhora no desempenho, contudo, Izat et al. (1990b) e Cave (1982) verificaram piora no desempenho.

O objetivo deste trabalho foi de avaliar o desempenho de frangos de corte machos alimentados com dietas contendo níveis crescentes da mistura dos ácidos fórmico e propiônico ( $70 \%$ e $30 \%$, respectivamente). 


\section{REVISÃO DE LITERATURA}

\subsection{Salmonella e avicultura}

Ao gênero Salmonella, enterobactéria gram-negativa, estão relacionados mais de 2.300 sorotipos, sendo que a maioria pode ser patogênica para animais de sangue quente ou frio, inclusive para humanos (Miles \& Butcher, 1993).

Apenas as espécies $S$. pullorum e $S$. gallinarum são agentes etiológicos de doenças específicas para as aves, causadores da pulorose e tifo aviário respectivamente.

Infeções paratíficas são causadas por um ou mais membros do gênero Salmonella, não constando deste grupo aqueles causadores específicos de doenças para as aves, podendo ocorrer em várias espécies animais, apresentando curso crônico ou agudo, sendo o caráter crônico da doença que faz das aves o maior reservatório da doença no ambiente (Williams, 1965).

Ao contrário da pulorose e do tifo aviário, as infeções paratíficas são de especial importância com relação a saúde publica devido a ocorrência freqüente de surtos de infeções em humanos. Berchieri Jr. (1991) atribui à capacidade das salmonelas paratíficas em permanecer no trato entérico dos animais a sua importância como fonte de contaminação dos seres humanos via produtos de origem animal.

Tifo aviário e pulorose determinam mortalidade nos lotes que podem variar de 0 a 100\%, dependendo da patogenicidade da cepa. Ambos os agentes etiológicos destas patologias têm baixa resistência fora do trato entérico das aves e sobrevivem por curto período de tempo (Silva, 1991). 
Berchieri Jr. et al. (1993a) relataram a ocorrência de um surto de infeção paratífica, causada por $S$. typhimurium, verificando que os sintomas surgiram a partir do 50 dia de vida das aves causando perdas devido a mortalidade e refugos acima do esperado. Padron (1990) relatou a ocorrência de um surto similar no México, causado por $S$. typhimurium, em pintos entre 1 e 2 semanas de idade, verificando retardo no crescimento e taxa de mortalidade e descarte entre 1,7 e $10,6 \%$ nas duas primeiras semanas de idade.

Durante o período de 1962 a 1991, Hofer et al. (1997) caracterizaram amostras de Salmonella colhidas em diversas regiões do Brasil classificando os sorotipos S. gallinarum, S. pullorum, S. typhimurium, S. heidelberg, S. enteritidis e $S$. infantis como os mais freqüentes.

\subsection{Fontes de contaminação}

Aves sãs podem ser infectadas com Salmonella por uma grande variedade de meios. Hinton (1992) define as principais fontes de contaminação como sendo as seguintes: os planteis de avós e de matrizes, a ração, o ambiente onde as aves estão sendo criadas, outros animais e o pessoal da granja.

De ave para ave a transmissão pode se vertical, transmissão transovariana, ou horizontal, por vários outros mecanismos (Berchieri Jr., 1995). Ambas ocorrem no matrizeiro e incubatório, Cox \& Bailey (1989) amostraram swabs de esteiras e fragmentos de ovos em vários incubatórios comerciais para verificar a presença de Salmonella, constatando que $80 \%$ dos fragmentos de ovos e $88 \%$ dos swabs de esteiras estavam contaminados, verificando que o incubatório é um dos pontos críticos para se prevenir a colonização do trato entérico de pintos por Salmonella.

Pintos são altamente susceptíveis à salmonelose; Cox et al. (1990)

observaram que 2 ufc (unidades formadoras de colônia) eram suficientes para colonizar o trato entérico de pintos até 3 dias de vida por via intracloacal. 
A $S$. enteritides, causadora de infeção paratífica em aves e humanos contamina as aves principalmente por meio de ratos, sendo que $14 \%$ dos casos de infeção em reprodutoras é atribuído a transmissão vertical (Optiz, 1992).

Além de incubatório e matrizes, rações e seus ingredientes, têm sido considerados como outra importante fonte de contaminação das aves e um dos principais pontos de controle da Salmonella em frangos de corte.

\subsection{Rações como fonte de contaminação por Salmonella}

A carne de aves, como uma das principais fontes alimentar no mundo, tem considerável significado com relação a saúde humana devido a ocorrência de Salmonella. Quando se adotam medidas higiênico sanitárias há a necessidade de se monitorar a possibilidade de reintrodução do agente no plantel. A ração e matérias primas de origem animal são talvez as mais importantes vias de transmissão de Salmonella para contaminação de animais e aves (Albuquerque, 1995).

Alguns estudos têm sido conduzidos no Brasil sobre a ocorrência de salmonelas, o que contribui para uma maior informação a respeito do tema. A ocorrência de Salmonella em ingredientes e rações em uma fábrica industrial foi estudada por Albuquerque et al. (1995) que constataram a ocorrência de Salmonella em 19,85\% das amostras (136 amostras) de matérias primas, sendo que, ingredientes de origem animal e derivados vegetais apresentaram $50 \%$ e $12,5 \%$ de amostras contaminadas, respectivamente.

Estudo sobre a ocorrência de Salmonella em rações para aves realizado por Berchieri Jr. et al. (1993b) colheu 50 amostras de ração em 4 fábricas diferentes totalizando 200 amostras. Foram encontrados 14 sorotipos com 29 linhagens resistentes a antibióticos, sendo que apenas uma das fábricas não apresentou contaminação.

Produtos de origem animal têm apresentado contaminações regulares por Salmonella. Berchieri Jr. et al. (1984) estudaram amostras de farinha de origem animal 
colhidas no estado de São Paulo e usadas para a elaboração de rações em três fábricas diferentes. Foi constatado que de 204 amostras, 77 estavam contaminadas por Salmonella, sendo que, os percentuais de positividade para cada tipo de farinha foi de $39 \%$ para a de carne e ossos, $16 \%$ para a de penas, $63 \%$ para a de penas e vísceras, $33 \%$ para a de vísceras e $50 \%$ para a de ossos.

Outro estudo realizado por Berchieri $\mathrm{Jr}$ et al. (1983) identificou contaminação por Salmonella em farinhas de carne e ossos e de penas da ordem de 13,56 e 3,72\% respectivamente. As farinhas de sangue, peixe, ossos, ostras, ovo e vísceras não apresentaram contaminação e os autores discutem que o nível de contaminação foi baixo em relação a literatura e que os fatores de contaminação destas matérias primas devem ser melhor estudados.

Hinton \& Mead (1992) alertam para a presença de Salmonella em alimentos e destacam que apesar do organismo nem sempre causar a doença em animais consumindo alimentos contaminados, em último caso, pode ocorrer enterite em pessoas que manipulam ou consomem carne e derivados.

Exposição de pintos recém nascidos à Salmonella no alimento constitui ponto crítico para colonização do trato digestivo das aves, visto que aves jovens são desprovidas de microflora intestinal completa resultando em que um número muito baixo do patógeno pode colonizar o trato digestivo dos pintos (Cox et al., 1990).

Um levantamento realizado por Cox et al. (1983) revelou que $58 \%$ das rações fareladas para aves e $92 \%$ das farinhas de carne e ossos estudadas estavam contaminadas por Salmonella, mostrando que este organismo está freqüentemente presente em rações e ingredientes e que a transferência ração-ave-humanos é uma importante forma de infeção e contaminação.

A contaminação de aves por Salmonella através de rações não está restrita pelo uso de ingredientes de origem animal. Vanderwal (1979) constatou que produtos de origem vegetal também podem apresentar contaminação, como os farelos de soja e girassol. 
Sorotipos de Salmonella são passíveis de serem encontrados inclusive no óleo. Grumbles \& Flowers (1961) analisando amostras de farelo de algodão e óleo de soja constataram a presença de 7 sorotipos de Salmonella em 5,14\% das amostras.

O controle da contaminação de rações é dependente de várias medidas higiênicas como o controle de roedores, animais de estimação e aves de vôo livre dentre outras (Navarro, 1995).

Insetos também podem ter grande importância na contaminação e recontaminação de rações. Kopanic Jr. et al.(1994) estudando baratas verificaram que estas têm um alto potencial de contaminação e transmissão de $S$. typhimurium, infectando membros sãos da colônia, água, alimento e comedouros. Os autores identificaram ainda em baratas provenientes de fábrica de ração e incubatório ( 5 e 8 amostras positivas respectivamente para 45 de cada) ocorrência de contaminação por Salmonella, concluindo que este inseto é um potencial vetor da infeção na produção de aves, contaminando rações e equipamentos.

\subsection{Uso de agentes antimicrobianos}

O uso de agentes antimicrobianos, principalmente antibióticos e quimioterápicos tem sido praticado na alimentação de aves e suínos desde a década dos anos 50 quando verificou-se que estes, fornecidos de forma contínua e a níveis subterapêuticos, melhoravam o desempenho destes animais (Soares, 1996).

As enterobactérias que habitam o trato alimentar de humanos e animais, apresentar resistência a antibióticos, podendo transmiti-la para outros microorganismos de mesma espécie, entre linhagens ou entre os de outra espécie como Escherichia coli, Shigella e Salmonella spp, podendo ser transmissão simples ou múltipla, quando mais de um agente antimicrobiano está envolvido (Smith, 1975).

Agentes antimicrobianos promotores de crescimento (APCs) modificam a flora intestinal do animal de uma forma tal que pode ser prejudicial para humanos, 
podendo selecionar bactérias resistentes a agentes antimicrobianos, aumentar a possibilidade da contaminação em humanos, transferência de plasmídeos resistentes para outros patógenos e estabelecer novos microorganismos resistentes. Outro fato referente a APCs é que eles aumentam a excreção entérica de patógenos pelo animal hospedeiro aumentando a densidade destes nas fezes, podendo levar a maiores riscos de contaminação de animais e humanos.

Casos em que sorotipos de Salmonella apresentam resistência total ou parcial a um ou mais tipos de agentes antimicrobianos têm sido relatados em animais, matérias primas e rações para aves.

A experiência da Holanda no controle da $S$. enteritidis foi apresentado por Goren (1995) relatando sucesso no uso combinado de enrofloxacina e microflora intestinal, porém, $S$. typhimurium foi reisolada 48 horas após o tratamento com dose terapêutica dupla durante três semanas.

Rambousek et al. (1993) relataram a ocorrência de surto de infeção paratifica causado por $S$. typhimurium em uma granja de frangos de corte em que, apesar do uso de agentes antibacterianos (ampicilina, cloranfenicol e furazolidona), a perda por mortalidade e refugos atingiu $8,8 \%$ do lote até a época do abate.

Ferreira et al. (1991) identificaram em $S$. gallinarum (obtidos de galinhas de postura) e $S$. pullorum (reprodutoras pesadas), isoladas entre 1988 e 1990 , o seguinte perfil de resistência: para $S$. gallinarum, cloranfenicol, estreptomicina, sulfadiazina, trimetropim, nitrofurantoina, lincomicina+estreptomicina, canamicina, carbecilina e ácido nalidixico; para $S$. pullorum, estreptomicina, ácido nalidíxico, sulfadiazina, trimetropim, nitrofurantoina, lincomicinatestreptomicina e carbenicilina. Os autores destacaram com surpresa a ocorrência de resistência principalmente às drogas que vinham sendo utilizadas nos tratamentos terapêuticos das aves.

Investigando a presença de Salmonella em uma granja avícola Berchieri Jr. et al. (1989), identificaram a farinha de carne e ossos como principal introdutor dos 22 sorotipos e verificando no antibiograma das salmonelas isoladas os seguintes percentuais de resistência: carbecilina, 94,23\%; tetraciclina, 92,31\%; ácido nalidixico, 73,08\%; 
nitrofurantoina, $65,38 \%$; cefalotina, $59,61 \%$; linco-spectin, $44,23 \%$; canamicina, $36,54 \%$; amicacina, 25,0\%; neomicina, 23,09\%; cloranfenicol, 19,23\%; ampicilina, 11,38\%; e cefoxitina, $1,92 \%$.

Dados referentes a um estudo entre 1979 e 1981 foram apresentados por Fageberg (1986) que, de 199 isolamentos de Salmonella, encontrou 82\% de resistência a drogas, sendo as mais comuns à sulfadiazina e (ou) streptomicina e (ou) tetraciclina, não apresentando resistência a amicacina, gentamicina, cloranfenicol, ácido nalidíxico ou tetraciclina+sulfametoxazole.

A respeito do uso racional de antibióticos e quimioterápicos em avicultura Colusi (1993) recomenda a caracterização do desequilibrio entre agente-hospedeiromeio, aconselhando a não utilização de antimicrobianos de amplo espectro, dosificação precisa objetivando o mínimo nível e não usar nenhum agente quando este não for estritamente necessário.

Um trabalho realizado por Manning et al. (1994) demonstrou o efeito de alguns antibióticos e anticoccidianos sobre a colonização cecal de pintos Leghorn expostos a flora entérica de aves normais por meio de cama usada e inoculando $S$. enteritidis resistente a bacitracina, novabiocina, ácido nalidíxico e nitrofurazona. Após o $13^{\text {o }}$ dia de idade verificou-se que as aves tratadas com novabiocina e nitrofurazona foram mais infectadas que as não tratados e apresentaram redução na produção de ácidos graxos voláteis nos cecos. Clortetraciclina, monensina ou nicarbazina não afetaram a colonização do trato entérico e a bacitracina aumentou a colonização cecal quando administrado continuamente.

\section{5 Ácidos orgânicos na alimentação de aves}

Ácidos orgânicos (AOs) são usados como aditivos em dietas de aves com frequêencia para diversos fins. Penz $\mathrm{Jr}$. et al. (1993) classificam os diferentes usos para estes ácidos como sendo: inibidores do desenvolvimento de fungos em matérias primas e 
rações; controle ou inibição da proliferação de enterobactérias como as do gênero Salmonella e E. coli; e como potencializador dos ganhos nutricionais das dietas aumentando a disponibilidade de nutrientes para a ave.

O termo AOs compreende uma grande gama de compostos que, em determinadas combinações, dependendo de qual é a finalidade, a que nível e em que condições é usado apresentam resposta diversa no desempenho das aves. Isto pode gerar confusão a respeito do efeito e modo de ação dos $\mathrm{AOs}$, sendo que, são necessárias definições mais claras sobre a química dos AOs.

\subsubsection{Definição e Química de AOs}

AOs são ácidos monocarboxílicos saturados de cadeia reta, abrangendo também os derivados deste grupo como os insaturados, hidroxílicos, fenólicos e multicarboxílicos. Nomes comuns dados a este grupo são graxas voláteis, lipofilicos e ácidos fracos ou carboxílicos. A cadeia reta do $\mathrm{AO}$ pode ser agrupada em ácidos graxos de cadeia curta (AGCC), média (AGCM) ou longa (AGCL) de acordo com o número de carbonos (1-6, 7-10 e 11 ou mais carbonos, respectivamente). Ácidos com 4 carbonos ou menos (fórmico, acético, propiônico e butírico) são líquidos em temperatura ambiente e miscíveis em água (Cherrington et al., 1991a).

Outra importante característica de cada AO é seu potencial de dissociação, expresso em valores de $\mathrm{pKa}$, onde $\mathrm{Ka}$ é a constante de dissociação ( $\mathrm{Ka}=[\mathbf{R}-\mathbf{C O O}]$ $\left[\mathbf{H}^{+}\right] /[\mathbf{R C O O H ]}$ ) e pKa representa -log Ka. Este valor representa o ponto de $\mathrm{pH}$ do meio em que há equilíbrio entre as formas dissociada e não dissociada do ácido (Rodwell, 1973).

Desta forma o $\mathrm{pH}$ de um meio pode ser representado por:

$$
\mathbf{p H}=\mathbf{p K a}+\log \frac{[\text { base }]}{[\text { ácido }]}
$$


Isto mostra que quando $\mathrm{pKa}=\mathrm{pH}$ teremos $50 \%$ de cada fração dissociada e não dissociada e quando o $\mathrm{pH}$ do meio for alterado em ${ }^{ \pm} 0,95$ do valor de $\mathrm{pK}$ do ácido teremos $10 \%$ de ácido não dissociado para $90 \%$ de ácido dissociado quando para mais e o contrário para menos (Jencks \& Regenstein, 1976).

A característica de dissociação dos AOs é de especial importância para sua ação como bactericida; o Quadro 1 mostra o pK de alguns ácidos de interesse.

Quadro 1 - Valores de pK de alguns ácidos orgânicos.

\begin{tabular}{ll}
\hline Ácido & $\mathrm{pK}$ \\
\hline Fórmico & 3,75 \\
Acético & 4,76 \\
Propiônico & 4,87 \\
Butírico & 4,81 \\
Lático & 3,86 \\
Cítrico & 3,$09 ; 4,75$ e 5,41 \\
Fumárico & 3,03 e 4,54 \\
\hline
\end{tabular}

Fasman (1976)

\subsubsection{Efeitos e modo de ação dos AOs como antibacterianos}

A literatura tem apresentado trabalhos que demonstram AOs como antagonistas da contaminação por Salmonella tendo os AGCC como os mais estudados.

$\mathrm{O}$ efeito do tratamento do alimento para aves com o inibidor de fungos Myco Curb, um produto comercial baseado em ácido propiônico, foi estudado por Rouse et al. (1988). Foi verificado uma redução do número de amostras fecais e intestinais contaminadas por Salmonella ao abate quando contaminaram frangos de corte nos dias 35 e 56 de criação com $S$. typhimurium e incluíram 0,5 e 1,0\% do produto na dieta na última semana de criação. 
McHan \& Shott (1992) observaram os efeitos da adição de AGCC (ácidos fórmico e propiônico) ao nível de $1 \%$ da dieta sobre a fixação de $S$. typhimurium nos cecos de pintos até 21 dias de idade. Os autores verificaram que ambos os ácidos reduziram $(\mathrm{P}<0,05)$ a fixação de Salmonella nos cecos quando comparados com o grupo controle não tratado.

Em outro estudo, McHan \& Shott (1993) avaliaram o efeito de AGCC sobre o crescimento de $S$. typhimurium em sistema "in vitro", usando uma mistura de AOs (ácidos fórmico, acético, propiônico, butírico, lático, succínico e fumárico), representando o conteúdo relativo do ceco de frangos alimentados com dietas sem medicamentos, adicionados aos meios de cultura em pH 5 e 6 . Os ácidos reduziram a formação de colônias em pelo menos $50 \%$ quando usado nas concentrações normais e mais de $80 \%$ quando dez vezes acima do normal; as maiores reduções ocorreram em $\mathrm{pH}$ 5 e devido ao ácido fórmico, propiônico e junção de todos os ácidos $(86,4 ; 87,6$ e 86,4\% de redução respectivamente).

A redução do tifo aviário foi testada por Berchieri \& Barrow (1996) pela incorporação de Bio-Add, um preparado comercial envolvendo a mistura de ácido fórmico e propiônico, em rações para pintos que foi inoculada com $S$. gallinarum e oferecida aos pintos no primeiro dia de vida. O estudo constatou a redução da mortalidade e morbidade de $76 \%$ para $33 \%$ nas aves tratadas com o produto.

Pesquisa realizada por Oliveira (1996) estudou o potencial de AGCC (ácidos lático, fórmico e propiônico), adicionados a ração de pintos de um dia (48 horas antes de serem fornecidas), no controle das $S$. typhimurium, $S$. enteritides, $S$. infantis e $S$. agona inoculadas na ração previamente esterilizada. Constatou-se que a associação entre os três ácidos adicionada ao nível de $0,4 \%$ na ração não foi eficiente no controle de $S$. typhimurium e S. agona, porém, a associação de ácido fórmico e propiônico na proporção de $70 \%$ para $30 \%$ foi eficiente para eliminar estes dois sorotipos $(0,4 \%$ da dieta), a $S$. enteritidis somente foi eliminada com $0,8 \%$ da mistura destes dois ácidos e para $S$. infantis o nivel de $0,8 \%$ somente inibiu o crescimento. A autora concluiu que 
houve sinergismo entre ácido fórmico e propiônico e que o tratamento de rações com estes AGCC é um meio eficaz de controle deste patógeno.

Os niveis de tolerância para a presença de Salmonella em alimentos na nutrição animal no Brasil tem sido preconizado como zero, ou seja, ausência em $25 \mathrm{~g}$ ou $\mathrm{ml}$ de amostra, a exemplo da legislação vigente em países como a Holanda, de onde alguns tópicos da legislação brasileira foi baseada ${ }^{1}$.

Um estudo realizado por Ziegenfus et al. (1992) avaliou a eficiência do sal Curbb (baseado em ácido propiônico) na eliminação de Salmonella em ingredientes para elaboração de rações em fábrica comercial de rações; os autores identificaram ausência de contaminação durante o período em que o produto foi utilizado na farinha de carne.

No que diz respeito ao modo de ação de AGCC como antimicrobianos algumas dúvidas a respeito ainda persistem.

Para os microorganismos, AOs podem atuar como fonte de carbono e energia ou como agente inibitório, dependendo da concentração do ácido, da facilidade deste entrar na célula e a capacidade da célula de metabolizar o ácido (Cherrington et al., 1991a).

O modo como AGCC entram na célula está bem estabelecido e apenas moléculas não dissociadas entram nestas e o transporte do AGCC normalmente é acompanhado do transporte de um $\mathrm{H}^{+}$do meio para a célula (Chu et. al., 1987).

Morte das células devido a presença de AOs no meio, ao contrário de outros agentes antimicrobianos, não está associado à lise de membranas celulares. Cherrinton et al. (1991b) constataram que E. coli e Salmonella spp., quando incubadas com 0,5 e $0,7 \mathrm{~mol} / 1$ de ácido fórmico ou propiônico, foram mortas em $90 \%$ da população após 30 e 60 minutos, sem que houvesse efeito sobre a integridade da membrana celular, descartando uma possível ação nesta parte da célula. Os autores discutem que o ácido propiônico foi um bactericida mais potente, provavelmente porque a $\mathrm{pH} 5$ (pH do meio extra celular) este ácido tem uma maior proporção de moléculas indissociadas que o

\footnotetext{
${ }^{1}$ SILVA, A. G. (MA/Serviço de Nutrição Animal - SNA, Chefe do SNA, Brasília-DF) Padrão de matérias primas destinadas à alimentação animal. Comunicação pessoal, 1991.
} 
ácido fórmico ( $43 \%$ para $5 \%$ respectivamente). A dissociação destas moléculas no citoplasma, reduzindo o pH e desnaturando o DNA de forma irreversível, é apresentado como o provável mecanismo de ação dos AGCC.

$O$ efeito antimicrobiano do ácido sórbico dissociado e não dissociado em células de várias bactérias, entre elas $E$. coli, foi verificado por Eklund (1983) constando que a forma não dissociada foi 10 a 600 vezes mais eficiente que o ácido dissociado em sua ação inibitória do desenvolvimento das bactérias.

Salmond et al. (1984), estudando o efeito de preservadores de alimento como o ácido propiônico, verificou que o $\mathrm{pH}$ intracelular de $E$. coli foi reduzido assim como a taxa de crescimento da bactéria. Em ensaio posterior verificou que a forma não dissociada estava intimamente relacionada com a redução do crescimento da bactéria. Os autores propõem que a inibição do crescimento é devido a inibição de função metabólica não identificada e de outras funções generalizadas, causada pela acidificação do citoplasma, porém, sem poder simplificar o modo de ação como sendo efeito simplesmente da redução do $\mathrm{pH}$ citoplasmático.

Os AGCC podem afetar a sintese de macromoléculas causando inibição do crescimento. Cherrington et al. (1990) verificaram que a síntese de DNA em E. coli foi afetada pela presença dos ácidos fórmico e propiônico e que as taxas de síntese de RNA, DNA, proteína, lipídio e parede celular foram reduzidas durante a exposição aos ácidos. A síntese de DNA foi mais sensitiva ao ácido propiônico que ao fórmico e o mecanismo com que o ácido atua não foi estabelecido, porém, pode estar envolvido uma ação mais específica do ânion do ácido.

\subsubsection{Desempenho e metabolismo de aves alimentadas com AOs}

$O$ efeito de AOs sobre o desempenho de frangos de corte tem se mostrado um assunto controverso e com poucos esclarecimentos. A grande variedade de AOs, combinações e formas de uso contribuem dispersando as informações a respeito. 
Os AOs têm sido aplicado como fungistáticos com freqüência em grãos destinados a nutrição animal. Stewart et al. (1977) avaliaram o desempenho de frangos de corte recebendo compostos antifúngicos em suas dietas, dentre eles o ácido propiônico ( 300 ou $500 \mu \mathrm{g} / \mathrm{g}$ ) verificando que, dentro dos níveis estudados do ácido propiônico, nenhum efeito foi verificado sobre peso vivo, consumo de ração ou eficiência alimentar de frangos de corte até a $6^{a}$ semana de idade.

Um estudo similar foi conduzido por Dilworth et al. (1979) que usaram propionato de cálcio $(0,10 \%)$ e ácido sórbico $(0,02 ; 0,04$ ou $0,06 \%)$ em dietas de frangos de corte e não verificaram efeito do propionato de cálcio sobre ganho de peso e eficiência alimentar, porém, o ácido sórbico melhorou numericamente a taxa de crescimento.

A atividade antifúngica do ácido propiônico foi observada por Dixon \& Hamilton (1981) em função de vários ingredientes da ração como o farelo de soja (FS), farinha de peixe (FP), farinha de subprodutos de aves (FSA), glúten de milho (GM), gordura (GO) e calcário (CA), adicionados ao milho e avaliados pela medida da produção de $\mathrm{CO}_{2}$ por fungos. Foi verificado antagonismo com FS, FP, FSA e CA, enquanto o GM não afetou a ação do ácido propiônico quando foi adicionado com óleo. Os autores observaram que a atividade do ácido foi reduzida provavelmente por efeito tamponante dos ingredientes antagonistas e que no caso da adição de gordura, esta pode ter aumentado a distribuição do ácido na dieta.

A mistura de ácido acético e propiônico (1:1) ou a adição isolada de cada um em níveis de 1,8 e $2,4 \%$ em grãos de sorgo úmido ( $20 \%$ de umidade), armazenados por $1,42,84,126$ e 168 dias, usados em níveis de 59 a $60 \%$ em dietas para frangos de corte até $\circ 2^{\circ}$ dia de idade não afetaram o consumo de ração, ganho de peso e conversão alimentar em estudos realizados por Garcia et al. (1995).

Os AOs quando adicionados à ração podem fornecer energia se metabolizados pela ave. Garlinch et al. (1976) avaliaram o valor de energia metabolizável (EM) para aves do milho tratado com 1,5\% de ácido propiônico e acético (mistura de 60:40), armazenado durante 10 semanas, constatando que, com base na matéria seca, não houve diferenças entre EM do milho tratado para o não tratado. 
$O$ valor energético de dietas contendo milho atacado por fungos para frangos de corte foi verificado por Bartov (1983) em função da adição de ácido propiônico $(0,3 \%)$ ou sulfato de cobre $(600 \mathrm{ppm})$. Dietas contendo o ácido foram totalmente prevenidas da redução de seu teor de gordura pela ação dos fungos não afetando os valores de EM.

A presença de ceco nas aves permite desenvolvimento de bactérias capazes de degradar alguns carboidratos que a ave não digere. Digestão devido a fermentação bacteriana no trato digestivo levanta a possibilidade de produção e absorção de produtos finais do metabolismo de microrganismos pelas aves. A digestibilidade da pectina solúvel em água e a produção de AOs em galos adultos intactos ou cecectomizados foi verificada por Carré \& Gomez (1994) constatando que, em aves intactas a maior parte dos produtos finais, resultantes da fermentação da pectina, foi efetivamente absorvida e metabolizada, sendo que, o ceco é o maior sítio de absorção dos ácidos graxos de cadeia curta, inclusive para aqueles produzidos na parte superior do trato digestivo, verificado por uma maior perda destes ácidos nas fezes de aves cecectomizadas.

Hume et al. (1993) estudaram a distribuição no organismo e tecidos de frangos de corte, 15 e 60 minutos após ingestão, do ácido $\left[1{ }^{14} \mathrm{C}\right]$ propiônico administrando 4 ou $120 \mu \mathrm{mol}$ oralmente. Após 15 minutos, 41 e $30 \%$ do total do marcador administrado foi encontrado em extratos do trato digestivo e tecidos de frangos que receberam 4 e $120 \mu$ mol respectivamente. Coleta de $\left[{ }^{14} \mathrm{C}_{\mathrm{CO}}\right.$ expirado durante 3 horas pós administração indicou que na ingestão oral de ácido propiônico ocorre ampla utilização (aproximadamente 75\%) como fonte de energia ou é metabolizado e assimilado nos componentes do sangue, sendo que, pouco ácido propiônico pode alcançar o trato digestivo inferior e o ceco.

Nagorna et al. (1990) observaram a influência dos ácidos propiônico (AP) e acético (AA) em frangos de corte até 4 semanas de idade em níveis de 50 e $130 \mathrm{mmol} /$, sobre a absorção de vitamina $\mathrm{C}$. Os autores constataram que AA nas concentrações de 50 e $130 \mathrm{mmol} / /$ deprimiu a absorção de vitamina C em 6 e 19\% no jejuno e em 13 e $20 \%$ no 
ceco, respectivamente, enquanto as mesmas doses de AP deprimiram em 15,4 e $45,4 \%$ no jejuno e 15 e $45 \%$ no ceco respectivamente, quando comparados com o controle.

Estudando o efeito de ácidos graxos voláteis sobre o ganho de peso de ratos submetidos a depleção de vitamina $B_{12}$ entre 2 e 4 semanas de idade, Dryden \& Hartman (1971) verificaram uma significativa redução no peso de ratos alimentados com dieta contendo ácido propiônico.

Ry's \& Koreleski (1974) observaram que o ácido propiônico (20 g/kg) deprimiu o peso de frangos de 1 a 28 dias de idade pelo comprometimento exercido pelo ácido sobre a disponibilidade da vitamina $B_{12}$, que faz a exigência destas aves aumentar.

A depleção da vitamina $B_{12}$ em galinhas submetidas a dietas sem vitamina $B_{12}$ e contendo ácido propiônico $(0,1,3$ e $4 \%)$, durante 2 meses de tratamento foi estudada por Ward et al. (1983), constatando que não foi possivel a depleção completa devido a dieta poder não ter sido devidamente purificada ou as reservas corporais serem grandes nestas aves.

Propionato e outros ácidos graxos de número ímpar de carbonos são gliconeogênicos. Propionato e coenzima A formarão propionil-CoA que é convertido em succinil-CoA, passando a integrar o ciclo dos ácidos tricorboxílicos (Beitz, 1996).

Ácido pantotênico (componente da $\mathrm{CoA}$ ) e vitamina $\mathbf{B}_{12}$ apresentam relação recíproca, sendo a exigência de ácido pantotênico maior para galinhas $B_{12-}$ depletadas. Ácido pantotênico também pode estar envolvido na síntese de ácido ascórbico, sendo sugerido ainda sua interrelação com ácido fólico e biotina. A exigência de vitamina $B_{12}$ depende do nível de colina, metionina e ácido fólico na dieta $e$ interrelacionado com ácido ascórbico no sangue (Scott et al. 1966). Estas interrelações nutricionais entre ácido pantotênico, cianocobalamina e ácido ascórbico no metabolismo das aves podem provocar uma piora no desempenho quando estas são alimentadas com dietas contendo AOs.

Retenção de cálcio nos ossos também é afetada pelo ácido propiônico. Ibardolaza et al. (1993) estudaram o efeito da adição de ácido propiônico $(0,1,2$ ou $3 \%$ da dieta) sobre a resistência a fratura e conteúdo de cálcio no osso tarsometatársico (tmt) 
de frangos de corte, verificando nos machos aumento na relação peso seco/peso fresco do tmt. Em fềmeas, diâmetro, peso seco e peso seco/peso fresco de tmt foram aumentados e, em ambos os sexos, elasticidade e resistência a fratura foram melhorados pela dieta contendo $3 \%$ de ácido propiônico.

Kaniawati et al., (1992) não verificaram nenhum efeito da adição de ácido fumárico $(0,5$ a $2,0 \%)$ ou lático $(0,25$ a $2,0 \%)$ sobre peso vivo, eficiência alimentar e mortalidade de frangos tratados com os ácidos.

Estudo do efeito de um inibidor de fungos ácido-básico propiônico (Mycocurb $^{\mathrm{R}}$ ) (níveis de 2,27, 4,54 e 9,07 kg/ton de ração), propionato de cálcio (4,54 e $9,07 \mathrm{~kg} /$ ton de ração) e ácido propiônico $(4,54$ e $9,07 \mathrm{~kg} /$ ton de ração) sobre a tensão muscular intestinal, peso vivo e $\mathrm{pH}$ do conteúdo intestinal em frangos de corte não constatou nenhum efeito sobre os parâmetros avaliados (Huff et al., 1994).

Alimentando frangos de corte até 42 dias de idade com dietas contendo $1,0 \%$ de ácido fórmico ou $1,45 \%$ de formato de cálcio, Izat et al. (1990a) não observaram nenhum efeito sobre peso vivo, eficiência alimentar ou viabilidade.

Patten \& Waldroup (1988) estudaram o uso dos ácidos fumárico $(0,0,5$, $1,0$ e $1,5 \%)$, formato de cálcio $(0,0,72,1,48,2,20$ e $2,89 \%)$ e as combinações entre os respectivos ácidos e seus níveis, sobre o desempenho de frangos de corte até 21 dias de idade. Os autores verificaram que 0,5 e $1,0 \%$ de ácido fumárico melhoraram o peso vivo dos frangos sem influenciar a eficiência alimentar, porém, a adição de formato de cálcio acima de $0,72 \%$ reduziu o peso corporal e eficiência alimentar.

Em estudo sobre o efeito dos ácidos graxos de cadeia curta e média sobre a ingestão de alimento em frangos de corte, Cave (1982) observou que o ácido propiônico (30g/ $\mathrm{kg}$ de dieta) deprimiu a ingestão voluntária de alimento em frangos entre 7 e 21 dias de idade; o autor também identificou uma tendência de diminuição da eficiência alimentar devido a presença desse nível de ácido propiônico.

Posteriormente, Cave (1984) verificou o efeito dos ácidos propiônico e lático sobre a ingestão voluntária de alimento em frangos de corte até 28 dias de idade 
constatando que, de $10 \mathrm{~g} / \mathrm{kg}$ até o nível de $100 \mathrm{~g} / \mathrm{kg}$ de ácido propiônico na dieta a ingestão era deprimida e até $30 \mathrm{~g} / \mathrm{kg}$ de ácido lático na dieta a ingestão não era afetada.

Pinchasov e Jensen (1989) estudaram a ingestão voluntária de alimento em frangos de corte devido ao fornecimento de ácidos graxos de cadeia curta com diferentes pesos moleculares. Estes autores verificaram que o ácido propiônico $(10,20$ e $30 \mathrm{~g} / \mathrm{kg})$, diminuiu linearmente a ingestão de alimento e que quando o ácido propiônico era neutralizado com $\mathrm{KOH}$, continuava deprimindo a ingestão linearmente. $O$ propionato deprimiu também a deposição de gordura abdominal.

O efeito do ácido propiônico tamponado (APT), adicionado à dieta de frangos de corte, sobre o desempenho e carcaça das aves foi motivo de estudo por Izat et al. (1990b). Os autores verificaram que para os níveis de $0,0,2,0,4$ e $0,8 \%$ de APT nenhum efeito foi observado sobre o crescimento, eficiência alimentar ou gordura abdominal, porém, o rendimento de carcaça foi melhorado nas fềmeas recebendo $0,8 \%$ de APT.

Pinchasov et al. (1993), tentando a restrição alimentar em reprodutoras de frango de corte até a décima semana de idade, usando dietas contendo $30 \mathrm{~g} / \mathrm{kg}$ de ácido propiônico, verificaram redução no consumo sem observar efeitos negativos no desempenho reprodutivo das aves.

Um nítido efeito anoréxico por parte do propionato de sódio (4\%) com redução do peso vivo, elevação da glucose sangǘnea e diminuição do peso do figado com redução do glicogênio foi verificado por Donaldson et al. (1994) em dietas para perus de um dia.

Usando ácido fumárico em níveis de $0,0,125,0,25$ e $0,5 \% \mathrm{em}$ dietas de frangos de corte até 49 dias de idade Skiner et al.(1991) verificaram melhora no desempenho das aves. $O$ ganho de peso de ambos os sexos e o peso vivo das fềmeas foram significativamente $(P<0,05)$ melhorados aos 49 dias pela adição de ácido fumárico $(0,125 \%)$, enquanto o consumo de ração, a eficiência alimentar e parâmetros de carcaça não foram afetados. 
Um estudo realizado por Runho et al. (1997) comparou níveis de ácido fumárico e adição de Nitrovin em lotes mistos de frangos de corte. Constatou-se melhora na conversão alimentar devido a redução do consumo sem afetar o ganho de peso e, em um segundo experimento para avaliar a energia metabolizável de rações contendo até $1 \%$ de ácido fumárico, foi observado aumento da energia metabolizável aparente corrigida pela retenção de nitrogênio das rações contendo o ácido.

$\mathrm{O}$ desempenho de frangos de corte alimentados continuamente com AOs foi estudado por Waldroup et al. (1995). Foram realizados três ensaios: no primeiro a suplementação de ácido lático (AL) níveis de 0,25 a $2 \%$ ou de ácido fórmico (AF), níveis de 0,5 a $2 \%$; no segundo, suplementação da mistura de ácido fórmico e propiônico (85\%:15\% respectivamente, AFP), níveis de 0,125 a 1\%; e no terceiro, suplementação de ácido cítrico (AC) níveis de 0,25 a $2 \%$. Os $\mathrm{AL}, \mathrm{AF}$ e $\mathrm{AC}$ não apresentaram efeitos sobre o desempenho das aves, AFP apresentou resultados inconsistentes no que diz respeito ao peso vivo e consumo de ração, não sendo afetada a conversão alimentar.

A alimentação de frangos de corte com uma mistura de ácidos orgânicos (Acidufeed, contendo os ácidos: lático, adípico, fosfórico e propiônico (20g); cítrico $(75 \mathrm{~g})$; fumárico $(15 \mathrm{~g})$; tartárico $(10 \mathrm{~g})$; aminoacético $(5 \mathrm{~g})$; e lecitina, pepsina e ácidos húmicos como veículo), não apresentou efeito sobre o desempenho de frangos de corte recebendo ou não $0,4 \%$ de Luprosil (ácido propiônico tamponado) e bacitracina de zinco a 50 ppm (Ferreira, 1995). 


\section{MATERIAL E MÉTODOS}

\subsection{Local}

O experimento foi conduzido no aviário experimental do Departamento de Genética da Escola Superior de Agricultura "Luiz de Queiroz", Piracicaba-SP.

\subsection{Aves experimentais}

Foram utilizados 1.000 pintos de um dia, machos da linhagem Ross, provenientes de incubatório comercial com peso médio inicial de $45,4 \mathrm{~g}$.

\subsection{Instalações e equipamentos}

$\mathrm{O}$ aviário experimental tem as dimensões de $30 \mathrm{~m}$ de comprimento, $12 \mathrm{~m}$ de largura, mureta lateral de alvenaria de $0,6 \mathrm{~m}$ de altura, piso de concreto com 26 boxes em duas fileiras de 13 boxes, separados por um corredor de $4,8 \mathrm{~m}$ de largura, sendo que, cada box possui área de $6,84 \mathrm{~m}^{2}$ com uma porta de acesso frontal. $\mathrm{O}$ aviário é coberto com telhas de barro, telado lateralmente até o teto e equipado com cortinas laterais.

Cada box foi equipado com um bebedouro tipo copo de pressão e a partir do $8^{\mathrm{a}}$ dia instalado um bebedouro tipo pendular. 0 comedouro foi do tipo tubular para pintos com capacidade para $3 \mathrm{~kg}$ e no $8^{\circ}$ dia instalado comedouro tipo tubular com 
capacidade para $25 \mathrm{~kg}$ e os comedouros para pintos e bebedouros tipo copo de pressão foram retirados no $10^{\circ}$ dia.

A cama foi de palha de arroz distribuída em camada de $10 \mathrm{~cm}$ sobre o piso dos boxes.

O aquecimento dos pintos até 14 dias de idade foi propiciado por lâmpada infravermelho de 250 watts distribuidas uma por box. Durante a primeira semana os pintos foram mantidos em círculos de contenção ao redor dos aquecedores de cada box $\mathrm{e}$ a cama foi forrada por papel. Após a primeira semana os círculos e o papel foram retirados.

\subsection{Manejo das aves e programa profilático}

Durante a primeira semana os pintos receberam aquecimento durante dia $\mathrm{e}$ noite $e$ as cortinas permaneceram fechadas. A partir da segunda semana diminuiram-se gradualmente as horas de aquecimento e aumentando as de cortina aberta de acordo com a temperatura ambiente e o comportamento das aves. As temperaturas foram obtidas por leituras diárias das temperaturas absolutas mínima e máxima a $20 \mathrm{~cm}$ do piso do galpão em termômetro de mínima e máxima de bulbo seco (Quadro 2).

Quadro 2 - Médias das temperaturas mínima e máxima observadas no período experimental.

Período Mínima Máxima

1 a 21 dias de criação 23,3 32,0

22 a 42 dias de criação 21,8 27,6

O fornecimento de água e ração foi à vontade e os bebedouros eram lavados duas vezes ao dia. 
Trinta dias antes do início do experimento instalações e equipamentos foram limpas, lavadas e desinfetadas, permanecendo as instalações com as cortinas fechadas até o início do experimento.

Os pintos foram vacinados no incubatório contra as doenças de Mareck, Gumboro e Bronquite Infecciosa e aos 10 dias de criação vacinou-se contra Newcastle via água de bebida.

\subsection{Período}

O período de criação foi de 42 dias, com as fases de criação divididas de 1 a 21 dias, 22 a 35 dias e 36 a 42 dias de idade.

\subsection{Ração experimental}

Foram utilizados três tipos de ração, sendo uma para cada fase de criação das estabelecidas acima. A composição das rações basais encontra-se no Quadro 3, tendo sido formuladas com base na composição de alimentos e para atender as exigências nutricionais estabelecidas em Rostagno et al. (1994).

\subsection{Tratamentos}

Os tratamentos foram a inclusão crescente de níveis $(0,0,25,0,5,1,0$ e $2,0 \%)$ da mistura dos ácido fórmico (70\%) e propiônico (30\%) determinados da seguinte forma:

1 - Dieta Basal (DB);

2 - $\mathrm{DB}+0,25 \% \mathrm{AO}$;

3 - DB + 0,5\% AO;

4 - DB + 1,0\% AO;

$5-\mathrm{DB}+2,0 \% \mathrm{AO}$. 
Quadro 3 - Composição percentual e níveis nutricionais calculados das dietas basais.

\begin{tabular}{|c|c|c|c|}
\hline INGREDIENTE & $1^{\mathrm{a}}$ FASE & $2^{\underline{a}}$ FASE & $3^{\mathrm{a}}$ FASE \\
\hline Milho & 54,606 & 58,984 & 59,037 \\
\hline Farelo de soja & 35,862 & 31,098 & 31,088 \\
\hline Óleo de soja & 3,596 & 4,270 & 4,252 \\
\hline Calcário calcítico & 0,938 & 0,920 & 0,920 \\
\hline Fosfato bicálcico & 2,268 & 2,061 & 2,060 \\
\hline DL-metionina & 0,140 & 0,128 & 0,128 \\
\hline Sal & 0,300 & 0,300 & 0,300 \\
\hline Supl. vitamínico' & 0,100 & 0,080 & 0,080 \\
\hline Supl. mineral $^{2}$ & 0,050 & 0,050 & 0,050 \\
\hline Cl-colina $(60 \%)^{3}$ & 0,080 & 0,040 & 0,020 \\
\hline Avoparcin $^{4}$ & 0,010 & 0,010 & 0,010 \\
\hline Anti-coccidiano & $0,050^{5}$ & $0,060^{6}$ & -.-.--- \\
\hline Amido $^{7}$ & 2,00 & 2,00 & 2,00 \\
\hline \multicolumn{4}{|c|}{ NIVEIS CALCULADOS } \\
\hline NUTRIENTE & $1^{2}$ FASE & $2^{\mathrm{a}}$ FASE & $3^{\mathrm{a}}$ FASE \\
\hline EM (kcal/kg) & 3.000 & 3.100 & 3.100 \\
\hline PB (\%) & 21,00 & 19,20 & 19,20 \\
\hline Metionina (\%) & 0,464 & 0,429 & 0,429 \\
\hline Met.+cist. (\%) & 0,810 & 0,750 & 0,750 \\
\hline Lisina $(\%)$ & 1,154 & 1,028 & 1,028 \\
\hline Triptofano (\%) & 0,283 & 0,255 & 0,255 \\
\hline Treonina (\%) & 0,824 & 0,754 & 0,754 \\
\hline Fósforo disp. (\%) & 0,50 & 0,46 & 0,46 \\
\hline Cálcio (\%) & 1,00 & 0,93 & 0,93 \\
\hline
\end{tabular}

1. Concentração por kg de produto: Vitamina A 10.000 .000 UI; vitamina D3 2.000.000 UI; vitamina E $30.000 \mathrm{UI}$; vitamina K3 3,0 g; vitamina B1 2,0 g; vitamina B2 6,0 g; vitamina B6 4,0 g; vitamina B12 $15 \mathrm{mg}$; ácido nicotínico $50,0 \mathrm{~g}$; selênio $2,5 \mathrm{~g}$.

2. Concentração por kg de produto: Manganês $16 \mathrm{~g}$; cobre $2 \mathrm{~g}$; zinco $100 \mathrm{~g}$; ferro $100 \mathrm{~g}$; iodo $2 \mathrm{~g}$; cobalto $20 \mathrm{~g}$.

3. Colina 417,208 e $104 \mathrm{mg} / \mathrm{kg}$ de ração respectivamente para as fases.

4. Avoparcin $10 \mathrm{ppm}$ na ração.

5. Nicarbazina $40 \mathrm{ppm}$ e maduramicina $3,75 \mathrm{ppm}$ na ração.

6. Lasalocida sódica $90 \mathrm{ppm}$ na ração.

7. Os tratamentos experimentais foram incluídos em substituição ao amido $(0 ; 0,25 ; 0,5 ; 1,0 ;$ e $2,0 \%$ da mistura de ácidos orgânicos na ração). 


\section{8 Ácidos utilizados.}

Foram usados ácidos líquidos, sendo: o ácido fórmico (Labsynth Produtos para Laboratório Ltda.), $\mathbf{8 8 \%}$ de pureza, corrigido para $100 \%$ na mistura dos ácidos e, a água contida neste ácido, não considerada na formulação da ração; e o ácido propiônico (Vetec Química Fina Ltda), com 99\% de pureza.

Os ácidos utilizados foram pesados e misturados na seqüência do ácido fórmico recebendo o ácido propiônico. Esta mistura era mantida em balde plástico transparente, adaptado com um sifão de borracha, usado no escoamento gradual dos ácidos do balde.

A mistura dos ácidos foi aplicada nas dietas na seguinte seqüência: foram misturados a princípio farelo de soja, óleo de soja e milho; em seguida adicionou-se a mistura dos ácidos que demorou em torno de 8 a 15 minutos; por último foi adicionado uma pré-mistura com os demais ingredientes misturados previamente em "Y" durante 12 minutos; após união de todos ingredientes, manteve-se a batida por 12 minutos.

A seqüência no misturador foi de início com a dieta basal e posteriormente pelas contendo AOs em ordem crescente. As dietas foram elaboradas 4 dias antes do fornecimento.

Para manuseio dos ácidos foram usados equipamentos de proteção individual (máscara para gases, óculos, luvas e capa) para os operadores que tinham contato com os ácidos. 


\subsection{Parâmetros estudados}

Os dados foram obtidos em pesagens realizadas semanalmente para acompanhamento do desempenho das aves pelos dados de peso vivo, ganho de peso, consumo de ração, conversão alimentar e mortalidade.

\subsubsection{Peso vivo médio}

Obtido dividindo-se o peso total da parcela pelo número de aves pesadas.

\subsubsection{Ganho de peso médio}

Determinado por diferença entre as pesagens de peso vivo médio atual e anterior.

\subsubsection{Consumo médio de ração}

O consumo de ração por ave foi determinado pela diferença entre a ração fornecida menos as sobras da parcela, dividido pelo número de aves da parcela. Nos casos em que houve morte de alguma ave no periodo, foram feitas correções para o consumo de ração pelo dia da ave morta.

\subsubsection{Conversão alimentar}

Calculado dividindo-se o consumo médio de ração por ave da parcela pelo ganho de peso médio por ave desta mesma parcela. 


\subsubsection{Mortalidade}

Número percentual de aves que morreram na parcela durante $o$ experimento.

\subsection{Delineamento experimental}

Foi utilizado o delineamento inteiramente casualizado com 5 tratamentos e 5 repetições com 40 aves por unidade experimental.

\subsection{Análise estatística}

Realizada segundo os procedimentos do GLM do programa SASStatistical Analyses System (SAS Institute, 1989), verificando análise de variância e regressão para os periodos de 1 a 21,22 a 42 e de 1 a 42 dias de idade.

O modelo estatístico considerado para análise de variância foi:

$Y_{i j}=m+t_{i}+e_{i j}$

onde:

$Y_{i j}=$ observação da variável no i-ésimo tratamento e da j-ésima parcela;

$\mathrm{m}=$ média geral;

$t_{i}=$ efeito do i-ésimo tratamento;

$e_{i j}=$ efeito residual devido ao erro aleatório. 
Variáveis consideradas:

1- peso vivo médio aos 21 e 42 dias de idade;

2- ganho de peso médio de 1 a 21, 22 a 42 e 1 a 42 dias;

3- consumo de ração médio por ave de 1 a 21,22 a 42 e 1 a 42 dias;

4- conversão alimentar de 1 a 21, 22 a 42 e 1 a 42 dias;

5- mortalidade de 1 a 21,22 a 42 e de 1 a 42 dias de idade. 


\section{RESULTADOS E DISCUSSÃO}

\subsection{Desempenho de 1 a 21 dias de idade.}

0 desempenho dos frangos de corte até 21 dias de idade foi afetado pela inclusão de AOs na ração. O peso vivo, consumo de ração e ganho de peso foram afetados $(P<0,01)$ pelos tratamentos, ao passo que conversão alimentar e mortalidade não $(\mathrm{P}>0,05)$. As médias dos tratamentos estão apresentadas no Quadro 4.

Quadro 4 - Desempenho das aves de 1 a 21 dias de idade.

\begin{tabular}{llllll} 
Trat. & PV $(\mathrm{kg})^{2}$ & CR $(\mathrm{kg})^{2}$ & GP $(\mathrm{kg})^{2}$ & CA $^{3}$ & MR (\%) \\
\hline DB & 0,736 & 1,080 & 0,690 & 1,56 & 0,5 \\
DB+0,25 & 0,732 & 1,132 & 0,687 & 1,65 & 1,5 \\
DB $+0,5$ & 0,729 & 1,111 & 0,684 & 1,62 & 1,0 \\
DB+1,0 & 0,725 & 1,082 & 0,679 & 1,59 & 1,5 \\
DB+2,0 & 0,669 & 0,945 & 0,624 & 1,51 & 0,5 \\
\hline CV (\%) & 2,57 & 7,09 & 2,72 & 5,98 & 150
\end{tabular}

\footnotetext{
Tratamentos indicados como dieta basal (DB) e sua respectiva porcentagem dos AOs.

${ }^{2}$ Peso vivo (PV), consumo de ração (CR) e ganho de peso (GP) médios de 1 a 21 dias com diferenças significativas pelo teste $F(P<0,01)$.

${ }^{3}$ Conversão alimentar (CA) e mortalidade (MR) médias sem diferenças significativa pelo teste $F$ $(\mathrm{P}>0,05)$.
} 
O peso vivo dos frangos até 21 dias foi afetado de forma quadrática $(\mathrm{P}=0,03$; Figura 1) pela inclusão dos ácidos na dieta. $\mathrm{O}$ nível de $0,5 \%$ reduziu levemente o peso dos frango e os níveis de 1 e $2 \%$ causaram uma redução mais acentuada, enquanto que $0,25 \%$ dos ácidos praticamente não alterou o peso vivo. $O$ nível de $2 \%$ reduziu em aproximadamente $60 \mathrm{~g}(9,5 \%)$ o peso vivo em relação aos frangos que não consumiram AOs em sua dieta.

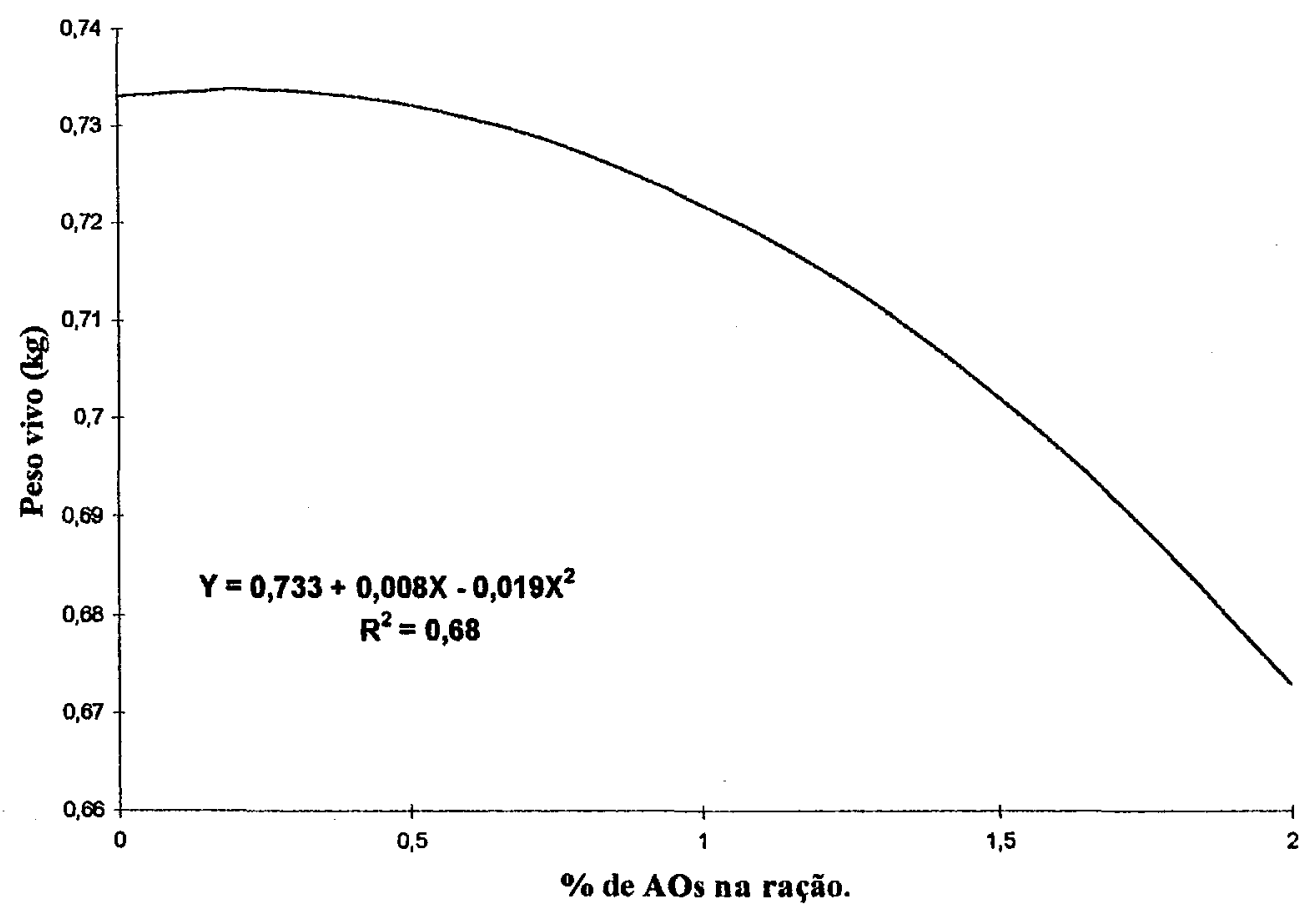

Figura 1 - Efeito dos AOs sobre o peso vivo aos 21 dias de idade.

O consumo de ração foi igualmente afetado pela inclusão dos AOs na dieta de forma quadrática ( $\mathrm{P}=0,06$; Figura 2). Os níveis de 0,25 e $0,5 \%$ de inclusão dos $\mathrm{AOs}$ causaram um ligeiro aumento no consumo de ração, ao passo que, $2 \%$ causou um acentuado decréscimo no consumo e o nível de $1 \%$ apresentou um consumo similar ao tratamento controle, sem adição de ácidos. 


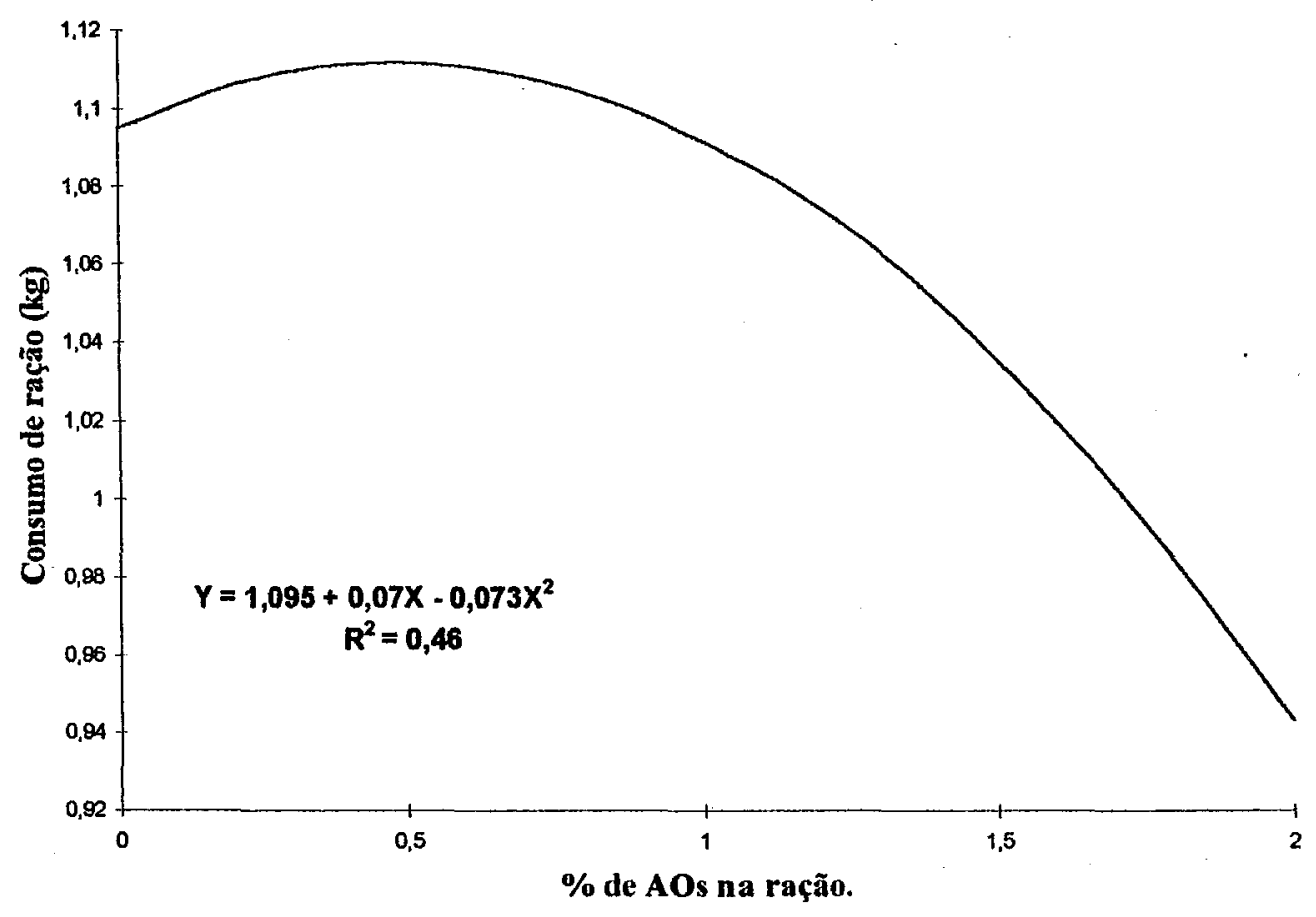

Figura 2 - Efeito dos AOs sobre o consumo de ração de 1 a 21 dias de idade.

O ganho de peso de 1 a 21 dias de idade foi afetado de maneira similar ao peso vivo aos 21 dias ( $\mathrm{P}=0,03$; Figura 3), apresentando um efeito quadrático da inclusão dos ácidos sobre o ganho de peso similar ao ocorrido para o peso vivo aos 21 dias. Até o nível de $0,5 \%$ o ganho de peso foi pouco afetado, porém, acima de $1 \%$ ocorre uma redução mais acentuada em comparação ao tratamento sem adição de ácidos. A redução no ganho de peso de 1 até 21 dias de idade foi de aproximadamente $60 \mathrm{~g}$, da mesma forma que para o peso vivo aos 21 dias. 


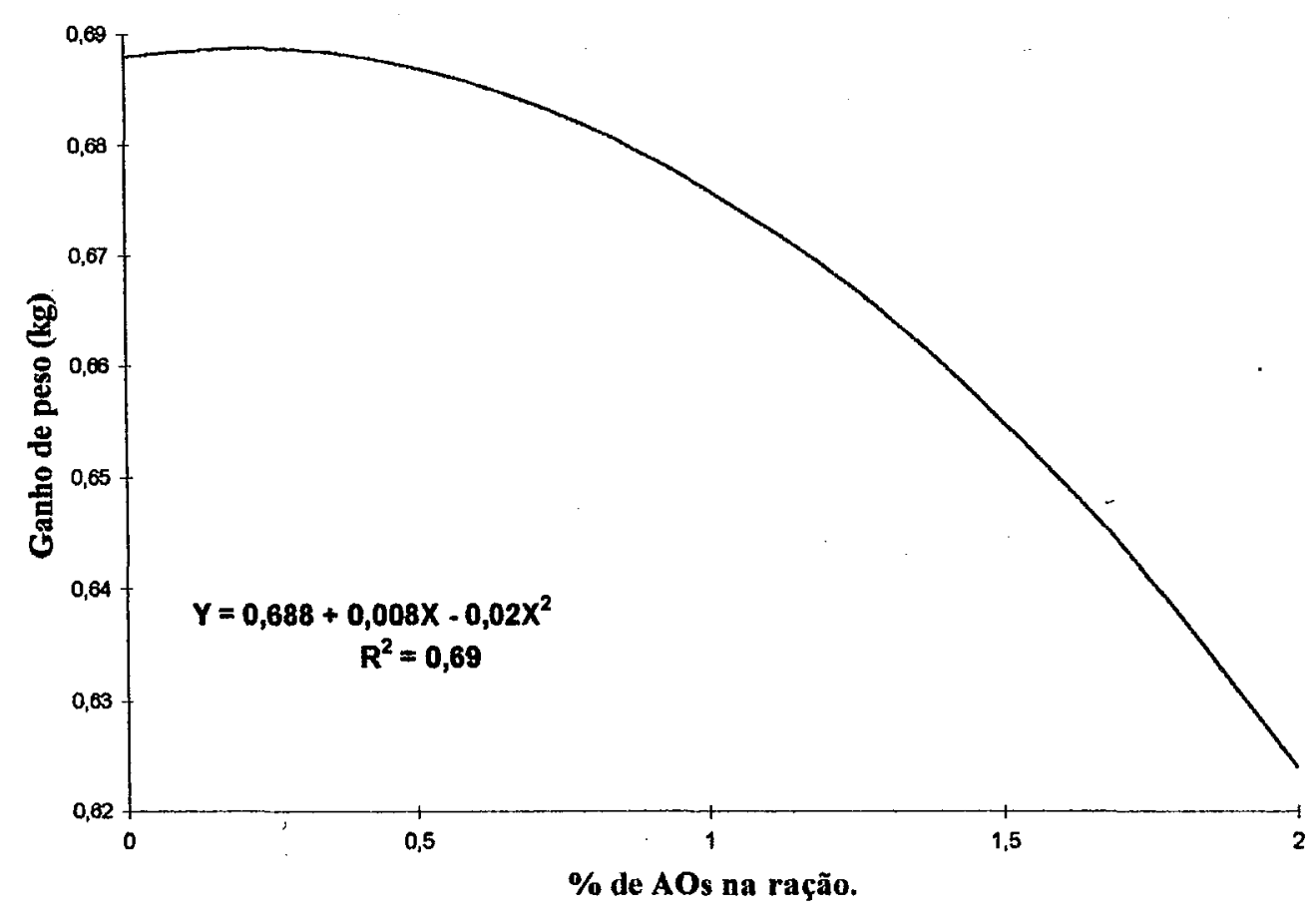

Figura 3 - Efeito dos AOs sobre o ganho de peso vivo de 1 a 21 dias de idade.

Patten \& Waldroup (1988) observaram que o formato de cálcio, em níveis acima de $0,72 \%$ da dieta, reduziu significativamente $(P<0,05)$ o peso vivo e piorou a eficiência alimentar em frangos até 21 dias de idade. Estes dados estão parcialmente de acordo com os observados neste estudo, concordando com relação ao peso vivo, porém, a conversão alimentar observada neste estudo não foi estatisticamente afetada ( $P>0,05)$, mas, numericamente, piorou nos níveis de 0,25 e $0,5 \%$ e foi melhorada com o nível de $2 \%$ dos AOs.

Waldroup et al. (1995) avaliaram o desempenho de frangos de corte alimentados com dietas contendo uma mistura de ácido fórmico e propiônico (85\%:15\%), constatando que até 21 dias de idade não havia diferenças significativas $(\mathrm{P}>0,05)$ no peso vivo, porém, observou-se uma tendência de declínio no peso das aves. Os autores observaram ainda que conversão alimentar e mortalidade não foram afetados pela inclusão da mistura dos ácidos. 
Estudos realizados por Izat et al. (1990b), avaliando o desempenho de frangos alimentados com $1,0 \%$ de ácido fórmico, indicaram que o peso vivo não foi afetado, ao contrário do que foi observado com a mistura dos ácidos fórmico e propiônico neste experimento, contudo, eficiência alimentar e mortalidade não foram afetados em ambos os estudos.

O ganho de peso observado neste estudo foi reduzido com a inclusão de níveis crescentes dos ácidos; isto está de acordo com dados obtidos por Cave (1982) que observou menor ganho de peso $(\mathrm{P}<0,05)$ para frangos alimentados com dietas contendo 3\% de ácido propiônico; o autor também verificou neste estudo redução do consumo de ração pela adição do ácido propiônico. No presente estudo a mistura de ácido fórmico e propiônico também reduziu o consumo de ração. Em outro estudo sobre a ação do ácido propiônico na ingestão de alimento, Cave (1984) observou que a inclusão deste ácido (até $5 \%$ ) reduziu o consumo.

$O$ efeito de $A G C C$ reduzirem o consumo de ração em frangos de corte foi observado também por Pinchasov \& Jensen (1989) que estudaram, dentre outros, os ácidos fórmico e propiônico, observando que apenas o ácido propiônico atuou reduzindo significativamente $(\mathrm{P}<0,05)$ o consumo.

A ingestão de AGCC também pode afetar o comportamento da ave, Cave (1978) observou que frangos injetados intraperitonealmente com ácido propiônico interromperam suas atividades alimentares em 0,5 a 1,5 horas, provavelmente devido a alguma ação sobre o mecanismo que regula a saciedade.

\subsection{Desempenho de 1 a 42 dias de idade}

De 1 a 42 dias de criação foi observada diferença significativa $(P<0,05)$ apenas para o consumo de ração. Peso vivo e ganho de peso não diferiram estatisticamente $(\mathrm{P}>0,05)$, porém, as médias de peso vivo e ganho de peso até 42 dia do tratamento que recebeu $2 \%$ da mistura dos AOs foi numericamente inferior, 
aproximadamente $80 \mathrm{~g}$ ( $3,5 \%$ do peso vivo e ganho de peso), que as médias das aves não tratadas. Da mesma forma, a conversão alimentar e mortalidade não foram significativamente $(\mathrm{P}>0,05)$ afetadas pelos tratamentos (Quadro 5).

Quadro 5 - Desempenho das aves de 1 a 42 dias de idade.

\begin{tabular}{lllllc} 
Trat. $^{1}$ & PV $(\mathrm{kg})^{2}$ & CR $(\mathrm{kg})^{3}$ & GP $(\mathrm{kg})^{2}$ & CA $^{2}$ & MR (\%) ${ }^{2}$ \\
\hline DB & 2,380 & 4,372 & 2,334 & 1,87 & 2,0 \\
DB+0,25 & 2,360 & 4,489 & 2,316 & 1,94 & 10,0 \\
DB+0,5 & 2,344 & 4,425 & 2,298 & 1,92 & 7,5 \\
DB+1 & 2,381 & 4,388 & 2,336 & 1,87 & 5,0 \\
DB+2 & 2,301 & 4,128 & 2,255 & 1,83 & 4,0 \\
\hline CV (\%) & 2,47 & 3,53 & 2,52 & 3,31 & 75,96
\end{tabular}

\footnotetext{
${ }^{1}$ Tratamentos indicados como dieta basal (DB) e sua respectiva porcentagem dos $\mathrm{AOs}$.

${ }^{2}$ Peso vivo (PV), ganho de peso vivo (GP), conversão alimentar (CA) e mortalidade (MR) médios para 0 periodo de 1 a 42 dias de idade sem diferença significativa pelo teste $F(P>0,05)$.

${ }^{3}$ Consumo de ração médio (CR) acumulado de 1 a 42 dias de idade com diferença significativa pelo teste $\mathrm{F}(\mathbf{P}<0,05)$.
}

Com relação ao peso vivo de frangos alimentados com AOs, Patten \& Waldroup (1988) verificaram que a adição de até $1,5 \%$ de formato de cálcio reduziu significativamente $(\mathrm{P}<0,05)$ o peso vivo médio de frangos até 42 dias de criação, reduzindo de $1,680 \mathrm{~kg}$ (dieta basal) para $1,598 \mathrm{~kg}$ (dieta com 1,5\% de formato de cálcio). Diferença desta magnitude também foi observada neste experimento, porém, sem diferença estatística $(P>0,05)$, sendo que, o peso vivo médio foi reduzido neste experimento de $2,380 \mathrm{~kg}$ (dieta basal) para $2,301 \mathrm{~kg}$ ( $2 \%$ de AOs na dieta, $1,4 \%$ de ácido fórmico).

Estudos realizados por Izat et al. (1990a), avaliando o efeito da adição do ácido propiônico tamponado (APT) constataram que a adição de até $0,8 \%$ de APT não afetou $(\mathbf{P}>0,05)$ o peso vivo dos frangos até 49 dias de criação; neste experimento a mistura dos AOs forneceu até $0,6 \%$ de ácido propiônico na ração. 
Izat et al. (1990b) alimentando frangos com dietas contendo ácido fórmico $(1,0 \%)$ e formato de cálcio $(1,45 \%)$ não observaram diferenças $(P>0,05)$ no desempenho das aves (peso vivo, eficiência alimentar e mortalidade) até 42 dias de idade. Kaniawati et al. (1992) não verificou efeito $(P>0,05)$ no desempenho de frangos de corte nos parâmetros de peso vivo, eficiência alimentar e mortalidade quando as aves foram alimentadas com dieta contendo uma mistura de ácido fórmico e propiônico (80\%:20\% respectivamente) em niveis de 0 a 1,0\% da dieta. Estas informações estão de acordo com os dados obtidos neste trabalho para os parâmetros observados, onde até o nível de $1 \%$ de inclusão as diferenças foram numericamente pequenas.

O consumo de ração de 1 a 42 dias de criação foi afetado de forma quadrática ( $P=0,08$; Figura 4) pela inclusão dos $\mathrm{AOs}$ na dieta. Os níveis de 0,25 e $0,5 \%$ de inclusão geraram um aumento no consumo de aproximadamente 117 e $53 \mathrm{~g}$, respectivamente, por ave no período de 1 a 42 dias de criação, quando comparados ao tratamento sem a adição de AOs. O nível de 1,0\% de inclusão da mistura de AOs proporcionou consumo similar ao nível zero e a adição de $2 \%$ da mistura dos ácidos reduziu o consumo em aproximadamente $240 \mathrm{~g}$ de ração no período.

Vários autores têm observado a ação do ácido propiônico como restritor do consumo quando adicionado em dietas de aves (Cave, 1982; Cave, 1984; Pinchasov \& Jensen, 1989; e outros). A redução acentuada no consumo das aves para o nível de $2 \%$ observado neste estudo está de acordo com a literatura, porém, o aumento de consumo para os níveis de 0,25 e $0,5 \%$ de inclusão dos ácidos neste experimento não foi observado na literatura.

A capacidade das aves em sentir sabor é uma questão pouco esclarecida; Appleby et al. (1992) afirma que o galo doméstico tem um sentido para o gosto dos alimentos bem desenvolvido. Estas rejeitam o sabor amargo (Gentle'; citado por Macari et al., 1994) e preferem sabor ácido em solução (Fuertes \& Kare, 1962). Isto pode, em parte justificar o comportamento quadrático observado no consumo de ração em função

\footnotetext{
' GENTLE, M. J. Britsh Poultry Science, v. 13, p. 144-155, 1972.
} 
dos níveis dos AOs na dieta e, como reflexo do consumo, foram obtidos os resultados de peso vivo, ganho de peso e conversão alimentar. Estas observações são válidas, porém, estudos mais aprofundados devem ser realizados a respeito da interferência dos AOs sobre o consumo de ração.

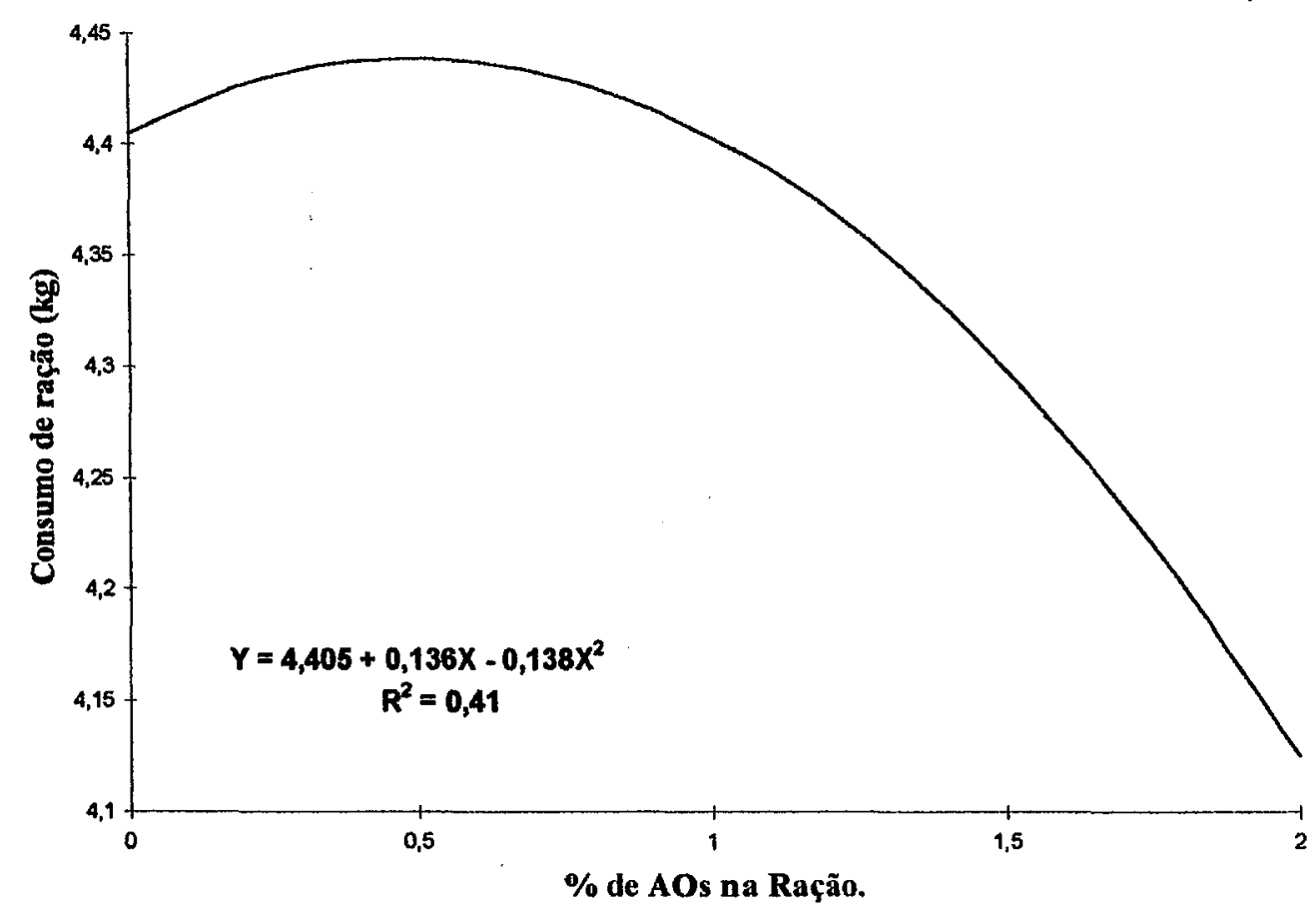

Figura 4 - Efeito dos AOs sobre o consumo de ração de 1 a 42 dias de idade.

$\mathrm{O}$ aumento de consumo para os niveis de 0,25 e $0,5 \%$ de AOs na dieta foi observado no período de 1 a 21 dias (Quadro 4 e Figura 2), 22 a 42 dias (Quadro 6, sem diferenças significativas, $\mathrm{P}>0,05$ ) e no período total, de 1 a 42 dias (Quadro 5 e Figura 4). A interferência dos ácidos sobre o consumo de ração afetou a conversão alimentar, em todos estes períodos, porém, apresentando apenas uma tendência, sem diferenças significativas $(P>0,05)$, piorando para os niveis de 0,25 e $0,5 \%$ e melhorando no nivel de $2 \%$ de inclusão dos AOs. 
Quadro 6 - Desempenho das aves de 22 a 42 dias de idade.

\begin{tabular}{lllll} 
Trat. $^{1}$ & CR $(\mathrm{kg})^{2}$ & GP $(\mathrm{kg})^{2}$ & $\mathrm{CA}^{2}$ & MR (\%) \\
\hline DB & 3,292 & 1,644 & 2,00 & 1,5 \\
DB+0,25 & 3,351 & 1,628 & 2,06 & 8,5 \\
DB+0,5 & 3,314 & 1,559 & 2,13 & 6,5 \\
DB+1 & 3,303 & 1,656 & 1,99 & 3,5 \\
DB+2 & 3,183 & 1,632 & 1,95 & 3,5 \\
\hline CV (\%) & 3,05 & 4,52 & 4,91 & 98,1 \\
\hline
\end{tabular}

\footnotetext{
${ }^{1}$ Tratamentos indicados como dieta basal (DB) e sua respectiva porcentagem dos AOs.

${ }^{2}$ Consumo de ração (CR), ganho de peso vivo (GP), conversão alimentar (CA) e mortalidade médios de 22 a 42 dias de idade sem diferença significativa pelo teste $F(P>0,05)$.
}

A conversão alimentar de 1 a 42 dias apresentou tendência $(\mathrm{P}=0,083)$ de piora com a inclusão de 0,25 e $0,5 \%$, não sendo afetada com $1,0 \%$ e melhorada com a inclusão de $2 \%$ dos AOs. Este resultado observado para a conversão alimentar foi observado em todas as fases de criação (Quadros 4,5 e 6).

A melhoria da conversão alimentar pela adição de altos níveis de AOs é pouco relatada na literatura: Pinchasov \& Jensen (1989) usando os ácidos acético e propiônico a níveis de até $3 \%$ não observaram efeito sobre a eficiência alimentar das aves; Izat et al. (1990a) usando até $0,8 \%$ de ácido propiônico tamponado não obtiveram efeito sobre a eficiência alimentar de frangos de corte; e Patten \& Waldroup (1988) verificaram que o formato de cálcio piorou a eficiência alimentar a partir de $1,5 \%$ de inclusão.

Kaniawati et al. (1992) e Waldroup et al. (1995) obtiveram com o uso da mesma mistura dos ácido fórmico e propiônico (80\%:20\%) efeito nulo sobre a eficiência alimentar até o nivel de $1 \%$ de inclusão dos AOs. Isto está de acordo com os dados obtidos neste trabalho em que o nível de inclusão de $1 \%$ dos AOs apresentou conversão alimentar similar ao nível zero, porém, estes trabalhos não estudaram níveis mais elevados de AOs.

A mortalidade das aves não foi afetada pelos tratamentos $(P>0,05)$ em todas as fases de criação como de acordo com vários autores (Izat et al., 1990a; 
Kaniawati et al., 1992; Waldroup et al., 1995). A mortalidade verificada no período de 22 a 42 dias de idade, provavelmente foi relacionada a condições climáticas desfavoráveis ocasionadas na $6^{3}$ semana de criação, independente do tratamento experimental. Silva (1995) estudou a mortalidade de frangos de corte até 47 dias de idade, em ambiente com temperaturas entre 37 e $39^{\circ} \mathrm{C}$, adicionando ácido fórmico ou fumárico em níveis de até $6 \%$, obtendo mortalidade de até $5 \%$, sem observar efeito dos ácidos sobre este parâmetro.

Até 21 dias de idade as diferenças no peso vivo entre os tratamentos com zero e $2 \%$ dos $\mathrm{AOs}$ foi aproximadamente de $60 \mathrm{~g}$ e até 42 dias de $80 \mathrm{~g}$. Isto indica que após 21 dias de criação os tratamentos afetaram muito pouco o crescimento das aves neste período e que a principal ação destes ácidos sobre o crescimento deve ter sido pela restrição de nutrientes, promovido pelo menor consumo das aves ingerindo $2 \%$ da mistura dos AOs, ocorrida nas 3 primeiras semanas de idade. $\mathrm{O}$ nível de $2 \%$ dos AOs promoveu uma redução de aproximadamente $9 \%$ no consumo de ração de 1 a 21 dias, de $3,3 \%$ de 22 a 42 e de $5,5 \%$ de 1 a 42 dias, quando comparado com a dieta basal.

Santoso et al. (1995) verificaram que a restrição alimentar de frangos entre o $10^{\circ}$ e o $15^{\circ}$ de vida reduziu o peso vivo e melhorou a conversão alimentar $(P<0,05)$. Em outro estudo realizado por Deaton (1995) constatou-se que a restrição alimentar entre o $7^{\circ}$ e $\circ 14^{0}$ dia de vida melhorou a conversão alimentar e reduziu o peso vivo $(\mathrm{P}<0,05)$, quando comparado às aves sem restrição alimentar.

Um estudo realizado por Zilkifli \& Fauzi (1996) analisando aves com e sem restrição alimentar constatou melhora na conversão alimentar e menor peso vivo aos 42 dias de idade para as aves alimentadas com restrição do consumo de alimento.

Leeson et al. (1995) estudando a resposta de frangos de corte a niveis de energia da dieta $(2.700$ a $3.300 \mathrm{kcal} / \mathrm{kg})$ não verificaram nenhum efeito quando a dieta era oferecida a vontade e a ingestão de energia, devido ao livre consumo, foi constante entre os tratamentos, porém, quando o consumo foi restringido, o ganho de peso foi reduzido $(P<0,01)$ juntamente com o nível de energia ingerida. 
Estes dados estão de acordo com os obtidos neste estudo em que o efeito dos AOs sobre o consumo de ração foram acompanhados pelos observados no peso vivo e ganho de peso, os quais, pioraram e na conversão alimentar que melhorou com o menor consumo de ração.

As informações da literatura e deste estudo indicam uma ação isolada de cada ácido da mistura (70\% de ácido fórmico : $30 \%$ de propiônico) sobre o desempenho das aves, particularmente com relação ao peso vivo e consumo de ração, porém isto não pôde ser estudado no presente trabalho, sugerindo mais estudos sobre a ação isolada destes ácidos. Futuros testes devem ser feitos também em condição tal que diferenças mínimas significativas em torno de 2,5 a $3 \%$ dos parâmetros observados possam ser identificadas.

\subsection{Considerações gerais}

A elaboração das dietas contendo AOs apresentou alguns problemas que devem ser relatados. $\mathrm{O}$ ácido fórmico apresenta intensa formação de gases, pode reagir vigorosamente ou ser explosivo quando em contato com agentes oxidantes e irrita a pele, quando em contato, formando pústulas (AOAC, 1990); o ácido propiônico, com odor forte e desagradável, é também muito agressivo ao contato com a pele, o que obriga para o manuseio destes ácidos o uso de óculos e máscara para gases orgânicos, luvas e capa.

Particularmente o ácido propiônico acarretou dificuldade no manuseio dissolvendo alguns materiais sintéticos do tipo plástico, o que impossibilitou a utilização de uma bomba tipo costal para a distribuição dos ácidos na ração dissolvendo vários de seus componentes. Usou-se como alternativa um balde plástico transparente, resistente a ação corrosiva dos ácidos, adaptado de um sifão de borracha para o escoamento gradual dos ácidos sobre a ração no misturador.

Sabe-se que estes ácidos podem causar queimaduras quando em contato com a pele, porém, um acidente (resvalo do braço em borda umedecida pelos ácidos no 
balde) com um dos operadores do misturador de ração, ocasionou queimaduras mesmo com a lavagem imediata da área atingida. Em face aos riscos oferecidos pelo manuseio de grandes quantidades destes ácidos, o uso de EPI e a presença de duchas no local de trabalho para prevenir eventuais acidentes é imprescindivel.

Suspeitou-se no início do experimento que estes ácidos poderiam ocasionar oxidação dos comedouros, desta forma, foram fotografados os pratos dos comedouros dos tratamentos com zero e $2 \%$ de AOs, já estando estes com sinais de oxidação. Ao final do experimento, os sinais de oxidação desapareceram devido a abrasão promovida pela ração em ambos os tratamentos, porém, nos pratos que receberam $2 \%$ de AOs observou-se uma maior deposição de material gorduroso que pode ser devido a associação dos ácidos com o óleo. Dixon \& Hamilton (1981), estudando a influência dos ingredientes da dieta sobre a ação antifúngica do ácido propiônico verificou que a adição de gordura melhorou a atividade antifúngica do ácido propiônico, provavelmente por promover maior dispersão deste ácido na ração.

Este fato pode ser de interesse devido ao fato de que a presença de insetos nos comedouros pode agir como um vetor de salmoneloses. Kopanic Jr. et al. (1994) verificou que baratas são vetores potenciais destas bactérias e apresentam alto grau de contaminação vertical contaminando locais que visitam como comedouros e bebedouros.

Com relação ao uso destes $\mathrm{AOs}$ o fator econômico pode ser preponderante na decisão do uso ou não deste produto. Os níveis determinados por Oliveira (1996) para se controlar salmonelas em rações e o desempenho das aves alimentadas com dietas contendo estes ácidos indicam que o nível de $0,8 \%$ dos $\mathrm{AOs}$ (nivel que controlou a $S$. enteritides) e $0,4 \%$ (nivel que controlou a $S$. typhimurium e $S$. agona) podem ser aplicados às dietas das aves, particularmente para níveis próximos de $1 \%$ de inclusão dos AOs.

O preço dos ácidos, o custo do espaço de inclusão na dieta e as dificuldades de operação associados aos efeitos sobre o desempenho das aves podem inviabilizar o uso destes ácido. 


\section{CONCLUSÕES}

- o uso da mistura dos ácidos fórmico e propiônico (70\%:30\%) até o nível de $2 \%$ na ração afeta o desempenho de frangos de corte;

- de 1 a 21 dias de idade a inclusão de altos níveis dos ácidos reduziu o peso vivo, o ganho de peso e consumo de ração das aves, tendo sido estes parâmetros afetados de forma quadrática;

- de 1 a 42 dias de idade apenas o consumo de ração foi afetado de forma quadrática reduzindo com altos níveis de inclusão dos AOs;

- o nível de $1 \%$ de inclusão dos AOs proporcionou desempenho similar ao das aves sem ácidos em suas dietas;

- o uso da mistura dos ácidos é dependente de fatores econômicos. 


\section{REFERÊNCIAS BIBLIOGRÁFICAS}

ALBUQUERQUE, R. Ocorrência e controle de Salmonella em ingredientes e fábricas de rações. In: SIMPÓSIO LATINO AMERICANO DE NUTRIÇÃO DE AVES E SUÍNOS, Campinas, 1995. Anais. Campinas: CBNA, 1995. p. 103-110.

ALBUQUERQUE, R.; ITO, N. M. K.; MIYAJI, C. I. Ocorrência de salmonelas em ingredientes, rações e "swabs" de pó colhidos em fábricas industriais de rações. In: CONFERÊNCIA APINCO'95 DE CIÊNCIA E TECNOLOGIA AVÍCOLAS, Curitiba, 1995. Trabalhos de pesquisa. Campinas: FACTA, 1995. p. 161-162.

ASSOCIATION OF OFFICIAL ANALYTICAL CHEMISTS - Official methods of analysis of the association of official analytical chemists. Arlington, 1990. v. 2, p. 1224, Appendix: laboratory safety.

APPLEBY, M. C.;HUGHES, O.; ELSON, H. A. Poultry production systems behavior, manegement and welfare. Great Britain: Red Wood Press, 1992. Cap. 1, p. 3-22: Poultry production.

BARTOV, I. Effect of propionic acid and copper sulfate on the nutritional value of diets containing moldy corn for broiler chicks. Poultry Science, v. 62, p.2195-2200, 1983.

BEITZ, D. C. Metabolismo dos carboidratos. In: SWENSON, M. J.; REECE, W. O. Dukes - fisiologia dos animais domésticos. 11 ed. Rio de Janeiro: Guanabara 1996. cap 24 , p. $398-411$. 
BECHIERI Jr., A. Contaminação por Salmonella em farinhas de origem animal utilizadas no preparo de rações. São Paulo, 1983. 83 p. Tese (Doutorado) Instituto de Ciências Biomédicas Universidade de São Paulo.

BERCHIERI Jr., A. Paratifo: Como podemos controlar ou erradica-lo a nível de produção. In: CONFERÊNCIA APINCO'91 DE CIÊNCIA E TECNOLOGIA AVÍCOLAS, Campinas, 1991. Anais. Campinas: FACTA, 1991. p. 49-62.

BERCHIERI Jr., A. Patologia e métodos de diagnóstico de SE em aves. In: CONFERÊNCIA APINCO'95 DE CIÊNCIA E TECNOLOGIA AVÍCOLAS, Curitiba, 1995. Anais. Campinas: FCTA, 1995. p. 1-5.

BERCHIERI Jr., A; BARROW, P. A. Reduction in incidence of experimental fowl typhoid by incorporation of a commercial formic acid preparation (Bio-Add) into poultry feed. Poultry Science, v. 75, p. 339-341, 1996.

BERCHIERI Jr., A.; ADACHI, S. Y.; CALZADA, C. T. et al. Farinha de carne como fonte de Salmonella em granja avícola. Pesquisa Veterinária Brasileira, v. 9. n. $1 / 2$, p. $9-12,1989$.

BERCHIERI Jr., A.; IRINO, S. N.; PAULILLO, A. Cet al. Contaminação por Salmonella em farinhas de origem animal utilizadas no preparo de rações. Pesquisa Veterinária Brasileira, v. 4, n. 3, p. 83-88, 1984.

BERCHIERI Jr, A.; AVILA, F. A.; PAULILLO, A. C. et al. Pesquisa de salmonelas em farinhas de origem animal utilizadas no preparo de rações. Científica, v. 11, n. 2 , p. $165-168,1983$.

BERCHIERI Jr., A.; DE CARVALHO, A. M.; FERNANDES, S. A. et al. Detection of Salmonella typhimurium in a broiler chiken flock. Revista de Microbiologia, v. 24, n. 3, p. 212-213, 1993a.

BERCHIERI Jr.; A.; FERNANDES, S. A.; IRINO, K. et al. Salmonella in poultry feeds in Brazil. Revista de Microbiologia, v. 24, n. 1, p. 22-25, 1993b.

BRASIL. Leis, decretos, etc. Portaria $\mathrm{n}^{\mathbf{0}} 1$ de 28 de janeiro de 1987. Diário Oficial da União, 12 fev., 1987, Seção 1, p. 3. 
CARRÉ, B.; GOMEZ, J. Digestibility of water-soluble pectin and organic acid losses in intact or cecectomized adult cockerels. Poultry Science, v. 73, p. 1881-1886, 1994.

CAVE, N. A. G. The influence of non-esterified fatty acids on feeding activity of chick. Poultry Science, v.57, p. 1124, 1978.

CAVE, N. A. G. Effect of dietary short and mediun-chain fatty acids on feed intake by chicks. Poultry Science, v. 61, p. 1147-1153, 1982.

CAVE, N. A. G. Effect of dietary propionic acid and latic acid on feed intake by chicks. Poultry Science, v. 63, p.131-134, 1984.

CHERRINGTON, C. A.; HINTON, M.; CHOPRA, I. Effect of short-chain organic acids on macromolecular synthesis in Escherichia coli. Journal Applied of Bacteriology, v. 68, p. $69-74,1990$.

CHERRINGTON, C. A.; HINTON, M.; MEAD, G. C. et al. Organic acids: Chemistry, antibacterial activity and practical applications. Advances in microbial physiology, v. 32, p.87-108, 1991a.

CHERRINGTON, C. A.; HINTON, M.; PEARSON, G. R. et al. Short-chain organic acids at pH 5,0 kill Escherichia coli and Salmonela spp. without causing membrane perturbation. Journal Applied of Bacteriology, v. 70, p. 161-165, $1991 \mathrm{~b}$.

CHU, I. M.; KEUER, T. A.; PAPOUTSAKIS, E. T. Formate transport, growth inhibition and the membrane protonmotive force in two methylotrophs (T15 and L3). Applied Microbiology and Biotechnology, v. 26, n. 1, p. 70-77, 1987.

COLUSI, A. D. Uso racional de antibioticos y quimioterapicos en avicultura. In: CONFERÊNCIA APINCO'93 DE CIÊNCIA E TECNOLOGIA AVÍCOLAS, Santos, 1993. Anais. Campinas: FACTA, 1993. p.67-72.

CORPET, D. E. Microbiological hazards and humans of antimicrobial growth promoter use in animal production. Revue de Medicine Veterinaire, v. 147, n. 12, p. 851862, 1996. /Resumo em CAB-Abstract, 1995-97/

COX, N. A; BAILEY, J. S. The role of the enviroment in the colonization of baby chick with salmonellae. Poultry Science, v. 68, sup. 1, p. 178, 1989. 
COX, N. A.; BAILEY, J. S.; BLANKENSHIP, L. C. et al. Research note: fifty percenty colonization for Salmonella typhimurium administered orally and intracloacaly to young broiler chick. Poultry Science, v. 69, p. 1809-1812, 1990.

COX, N. A.; BAILEY, J. S.; THOMASON, J. E. Salmonella and other Enterobacteriaceae found in comercial poultry feed. Poultry Science, v. 62, p. $2169-2175,1983$.

DEATON, J. W. The effect of early feed restriction on broiler performance. Poultry Science, v. 74, n. 8, p. 1280-1286, 1995.

DESOUZART, O: Com as barbas de molho. Avicultura Industrial, v. 87, n. 1045, p. 26-28, jun., 1997.

DILWORTH, B. C.; CHEN, T. C.; DAY, E. J. Fungistatic compounds in broiler production. 1-Effect on rate of gain and feed utilization. Poultry Science, v. 58, p. $1445-1450,1979$.

DIXON, R. C.; HAMILTON, P. B. Effect of feed ingredients on the antifungal activity of propionic acid. Poultry Science, v. 60, p. 2407-2411, 1981.

DONALDSON, W. E.; CHRISTENSEN, V. L.; FERKET, P. R. Administration of propioniate to day-old turkeys. Poultry Science, v. 73, p. 1249-1253, 1994.

DRYDEN, L. P.; HARTMAN, A. M. Effect of vitamin $B_{12}$ on metabolism in the rat of volatile fatty acids. Journal of Nutrition, v. 101, n. 1, p. 589-592, 1971.

EKLUND, T. The antimicrobial effect of dissociated and undissociated sorbic acid at different pH level. Journal Applied of Bacteriology, v. 54, p. 383-389, 1983.

FAGEBERG, D. J. Salmonella incidence and antimicrobial resistence in fecal and feed sample of production broilers, beef catle and swine end swine at slaughter plants in the united states - A four year study. Journal of Animal Science, v. 62, sup. 3, p. $33-42,1986$.

FASMAN, G. D. Handbock of biochemistry and molecular biology. 3 ed. Cleveland: CRC Press, 1976. p. 151-269: Physical and chemical data/Heat of proton ionization, pK and releted thermodynamic quantites. 
FERREIRA, A. J. P.; ITO, N. M. K.; MYIAJ, C. I. et al. Incidência, resistência a drogas antimicrobianas, patogenicidade e alguns fatores de virulência de Salmonella gallinarum e $S$. pullorum. In: CONFERÊNCIA APINCO'91 DE CIÊNCIA E TECNOLOGIA AVÍCOLAS, Campinas, 1991. Trabalhos de pesquisa. Campinas: FACTA, 1991. p. 264-265.

FERREIRA, V. Q. Desempenho de frangos de corte alimentados com ração contendo ácidos orgânicos. Viçosa, 1995. 63 p. Dissertação (Mestrado) - Universidade Federal de Viçosa.

FUERST, W. F.; KARE, M. R. The influence of $\mathrm{pH}$ on fluid tolerance and preferences. Poultry Science, v. 41, p. 71-77, 1962.

GARCIA, D. C.; MAIER, J. C.; ELIAS, M. C. Desempenho de pintos alimentados com grãos de sorgo úmido tratados com ácidos orgânicos. Revista da Sociedade Brasileira de Zootecnia, v. 24, n. 1, p. 62-69, 1995.

GARLINCH, J. D.; WYATT, R. D.; HAMILTON, P. B. The metebolizable energy value of high moisture corn preserved with a mixture of acetic and propionic acids. Poultry Science, 55, p. 225-228, 1976.

GOREN, E. Experiência com controle de Salmonella enteritidis na Holanda de 19891995. In: CONFERÊNCIA APINCO'95 DE CIÊNCIA E TECNOLOGIA AvíCOLAS, Curitiba, 1995. Anais. Campinas: FACTA, 1995. p. 143-148. GRUMBLES, L. C.; FLOWERS, A. I. Epidemiologi of paratyphoid infectioms in turkey. Journal of the American Veterinary Medical Association, v. 138, p. 261$262,1961$.

HINTON, M. Infeções causadas por Salmonella em aves e seus respectivos controles. In: CONFERÊNCIA APINCO'92 DE CIÊNCIA E TECNOLOGIA AVÍCOLAS, Santos, 1992. Anais. Campinas: FACTA, 1992. p. 119-122.

HINTON, M.; MEAD, G. C. Bacterial pathogens in animal feed and their control. World's Poultry Science, v. 48, p. 72-73, 1992. 
HOFER, E.; SILVA FILHO, S. J.; REIS, E. M. F. Prevalência de sovares de Salmonella isolados de aves no Brasil. Pesquisa Veterinária Brasileira, v. 17, n. 2, p. 55-62, 1997.

HUFF, W. E.; BALOG, J. M.; BAYYARI, G. R. et al. The effect of Mycocurb ${ }^{R}$, propionic acid, and calcium propionate on the intestinal stregth of broiler chickens. Poultry Science, v. 73, p.1352-1356, 1994.

HUME, M. E.; CORRIER, D. E.; IVIE, G. W. et al. Metabolism of $\left[{ }^{14} \mathrm{C}\right]$ propionic acid in broiler chicks. Poultry Science, v. 72, p.786-793, 1993.

IBARDOLAZA, E. I.; ISSHIKI, Y.; YAMAUCHI, K.; NAKAHIRO, Y. Effectss of dietary propionic acid on breaking strength and calcium content of the tarsometatarsal bone in broiler chickens. Japanese Poultry Science, v. 30, n. 3, p. 175-182, 1993. /Resumo em CAB Abstracts on CD-ROM,1993-94/

IZAT, A. L.; ADAMS, M. H.; CABEL, M. C. et al. Effects of formic acid or calcium formate in feed on performance and microbiological characteristics of broilers. Poultry Science, v. 69, p.1876-1882, 1990a.

IZAT, A. L.; TIDWELL, N. M.; THOMAS, R. A. et al. Effects of a buffered propionic acid in diets on the performance of broiler chickens and on microflora of intestine and carcass. Poultry Science, v. 69, p. 818-826, $1990 \mathrm{~b}$.

JENCKS, W. P.; REGENSTEIN, J. Ionization of acid and bases. In: FASMAN, G. D. Handbock of biochemistry and molecular biology. 3 ed. Cleveland: CRC Press, 1976., p. 305-352: Physical and chemical data.

KANIAWATI, S.; SKINER,. J.; WALDROUP, P. et al. Effects of feeding organic acids to broilers on performence and salmonellae colonization of the ceca and/or contamination of the carcass. Poultry Science, v. 71, sup. 1, p. 159, 1992. KOPANIC Jr., R. J.; SHELDON, B. W.; WRIGTH, C. G. Cockoaches as vector of Salmonella, laboratory and trials. Journal of Food Protection, v. 57, n. 2, p. 125 $132,1994$.

LEESON, S.; CASTON, L.; SUMMERS, J. D. Broiler response to diet energy. Poultry Science, v. 74, n. 4, p. 529-535, 1995. 
MACARI, M.; FURLAN, R. L.; GONZALES, E. Fisiologia aviária aplicada a frangos de corte. Jaboticabal: FUNEP, 1994. cap. 4, p. 45-68: Ingestão de alimentos: mecanismos regulatórios.

MANNING, J. G.; HARGIS, B. M.; HINTON Jr., A. et al. Effect of selected antibiotics and coccidial on Salmonella enteritides cecal colonization and orgam invasion in leghorn chicks. Avian Diseases, v. 38, n. 2, p. 256-261, 1994.

McHAN, F.; SHOTTS, E. B. Effect of feeding selected short-chain fatty acids on the in vivo attachment of Salmonella typhimurium in chick ceca. Avian Diseases, v. 36, p. 139-142, 1992.

McHAN, F.; SHOTTS, E. B. Effect of short-chain fatty acids on the growth of Salmonella typhimurium in an in vitro system. Avian Diseases, v. 37, p. 396-398, 1993.

MILES, R. D.; BUTCHER, G.D. Salmonella controling it in the broiler egg industries. Feedstuffs, v. 65 , n. 42 , p. 1, 24-34, 1993 .

NAGORNA, S. B.; LAZUGA A. A.; LECHOWSKI, J. The role of volatile fatty acids in the absorption of vitamin C. Medycyna Weteryjna, v. 46, n. 6, p. 203-205, 1990. /Resumo em CAB Abstracts on CD-ROM, 1990-1991/

NAVARRO, M. P. Infeção por Salmonella enteritidis em reprodutoras pesadas na América Latina. In: CONFERÊNCIA APINCO'95 DE CIÊNCIA E TECNOLOGIA AVÍCOLAS, Curitiba, 1995. Anais. Campinas: FACTA, 1995. p. 9-16.

OLIVEIRA, E. O uso de ácidos graxos de cadeia curta no controle de Salmonella em rações de aves. Piracicaba, 1996, 72p.. Dissertação (Mestrado)- Escola Superior de Agricultura "Luiz de Queiroz", Universidade de São Paulo.

OPTIZ, H. M. Progress being made in Salmonella enteritides reduction on the farm. Poultry Digest, v. 31 , n. 1 , p. 16-22, 1992.

PADRON, M. N. Salmonella typhimurium outbrek in broiler chicken flock in Mexico. Avian Diseases, v. 34, p. 221-223, 1990. 
PATTEN, J. D.; WALDROUP, P. W. Use of organic acids in broiler diets. Poultry Science, v. 67, p. 1178-1182, 1988.

PENZ Jr., A. M.; SILVA, A. B.; RODRIGUES, O. Ácidos orgânicos na alimentação de aves. In: CONFERÊNCIA APINCO'93 DE CIÊNCIA E TECNOLOGIA AVíCOLAS, Santos, 1993. Anais. Campinas: FACTA, 1993. p. 111-119.

PINCHASOV, Y.; JENSEN, L. S. Effect of short-chain fatty acids on voluntary feed of broiler chicks. Poultry Science, v. 68, p. 1612-1618, 1989.

PINCHASOV, Y.; GALILI, D.; YONASH, N. et al. Effect of feed restriction using selfrestricting diets on subsequent performance of broiler breeder females. Poultry Science, v. 72, p. 613-619, 1993.

RAMBOUSEK, M. J.; CARVALHO, A. M.; FERNANDES, S. A. et al. Salmonelose aviária - relato de ocorrência de paratifo aviário e tifo aviário em frangos de corte. In: CONFERÊNCIA APINCO'93 DE CIÊNCIA E TECNOLOGIA AVÍCOLAS, Santos, 1993. Trabalhos de pesquisa. Campinas: FACTA, 1993. p. 58.

RODWELL, V. Química orgânica (revisão sumária). In:HARPER, H. A. Manual de química fisiológica. São Paulo: Atheneu, 1973. p. 541-551.

ROSTAGNO, H. S.; SILVA, D. J.; COSTA, P. M. A. et al. Composição de alimentos e exigências nutricionais de aves e suínos (tabelas brasileiras). 6 ed. Viçosa: Imprensa Universitária, 1994. 57 p..

ROUSE, J.: ROLOW, A.; NELSON, C. E. Effect of chemical tretment of poultry feed on survival of Salmonella. Poultry Science, v. 67, p. 1225-1228, 1988.

RUNHO, R. C.; SAKOMURA, N. K.; KUANA, S. et al. Uso do ácido orgânico (ácido fumárico) nas rações de frangos de corte. Revista Brasileira de Zootecnia, v. 26, n. 6, p. 1183-1191, 1997.

RY'S, B. B.: KORELESKI, J. The effect of dietary propionic acid on the requerement of chicks for vitamin $B_{12}$. The Britsh Journal of Nutrition, v. 31, p. 143-146, 1974.

SALMOND, C. V.; KROLL, R. G.; BOTH, I. R. The effect of food preservatives on $\mathrm{pH}$ homeostasis in Escherichia coli. Journal of General Microbiology, v. 130, p. 2845-2850, 1984. 
SANTOSO, U.; TANAKA, K.; OHTANI, S. Does feed- restriction refeeding program improve growth characteristics amd body composition of broiler chicken? Animal Science and Technology, v. 66, n. 1, p. 27-35, 1995. /Resumo em CAB-Abstract on CD-ROM, 1995/

SAS INSTITUTE. SAS/STAT: user's guide, version 6. Cary, NC:SAS Institute Inc. SCOTT, M. L.; NESHEIM, M. C.; YOUNG, R. J. Nutrition of the chicken. Ithaca: M. L. Scott \& Associates, 1966. cap. 4, p. 106-257: The Vitamins.

SILVA, A. V. F.; FLEMMING, J. S.; SANTI, R. P. et al. Use of fumaric acid to prevent heat stress and sudden death in chickens. Revista do Setor de Ciências Agrárias, v. 14, n. 1-2, p. 77-82, 1995. /Resumo em CAB-Abstract on CD-ROM, 1996-98/ SILVA, E. N. Salmonelose: Problemas atuais de patologia aviária e saúde pública. In: CONFERENCIA APINCO'91 DE CIÊNCIA E TECNOLOGIA AVÍCOLAS, Campinas, 1991. Anais. Campinas, SP: FACTA, 1991. p. 49-62.

SILVA, E. N. Mitos e realidade no controle de Salmonella enteritidis em matrizes. In: SIMPÓSIO INTERNACIONAL SOBRE MANEJO DE MATRIZES E INCUBAÇÃO, Campinas, 1997 Anais. Campinas: FACTA, 1997. p. 73-86. SKINER, J. T.; IZAT, A. L.; WALDROUP, P. W. Research note: Fumaric acid enhances performance of broiler chickens. Poultry Science, v. 70, p. 1444-1447, 1991.

SMITH, H. W. Clinical problems of preventive medicine. World's Poultry Science, v.31, n. 2, p. 104-115, 1975.

SOARES, L. L. P. Painel - restrição e uso de aditivos (promotores de crescimento) em rações de aves. Visão do fabricante. In: CONFERÊNCIA APINCO'96 DE CIÊNCIA E TECNOLOGIA AVÍCOLAS, Curitiba, 1996. Anais. Campinas: FACTA, 1996. p. 27-36.

STEWART, R. G.; WYATT, R. D.; KIKER, J. Effect of comercial antifungal compounds on the performance of broiler chickens. Poultry Science, v. 56, p. 1664-1666, 1977. 
VANDERWAL, P. Salmonella control of feedstuffs by pelleting or acid tretment.

World's Poultry Science, v. 35, p. 70-78, 1979.

WALDROUP, A.; KANIAWATI, S.; MAUROMOUSTAKOS, A. Performance characteristics and microbiological aspects of broilers fed diets suplemented with organic acids. Journal of Food Protection, v. 58, p. 482-489, 1995.

WARD, N. E.; MAURICE, D. V.; JONES, J. E. Vitamin $B_{12}$ status of hens fed propionic acid. Poultry Science, v.62, suppl.1, p. 1521, 1983.

WESTERFELD, B. L.; ADAMS, A. W.; ERWIN, L. E. et al. Effect of a chemical additive on Salmonella in poultry feed and host birds. Poultry Science, v. 42, n. 2, p. 1319-1323, 1970.

WILLIAMS, J. E. Paratyphoid and arizona infections. In: BIESTER, H. E.;

SCHWARTE, L. H. Diseases of poultry. 5. ed. Ames: The Iowa State University Press, 1965. cap. 9, p. 260-328.

ZIEGENFUS, S. J.; ROLOW, A. M.; NELSON, C. E. Practical control of Salmonella in a comercial rendering operation with a Salmonella control agent. In: WORLD'S POULTRY CONGRESS, Amsterdam, 1992. Procedings. Amsterdam: Ponsen \& Looijen, 1992. v. 1, p. 445-447.

ZULKIFLI, I; FAUZI, A. M. Behaviour and performance of fasted broilers under high temperature and humidity. Journal Veterinar Malaysia, v. 8, n. 1, p. 1-6, 1996. /Resumo em CAB-Abstract on CD-ROM, 1996-98/ 